\title{
On the relative absorption strengths of water vapour in the blue wavelength range
}

\author{
J. Lampel ${ }^{1, a}$, D. Pöhler ${ }^{1}$, J. Tschritter ${ }^{1}$, U. Frieß ${ }^{1}$, and U. Platt ${ }^{1}$ \\ ${ }^{1}$ Institute of Environmental Physics, University of Heidelberg, Heidelberg, Germany \\ ${ }^{a}$ now at: Max Planck Institute for Chemistry, Mainz, Germany \\ Correspondence to: J. Lampel (johannes.lampel@iup.uni-heidelberg.de)
}

Received: 19 April 2015 - Published in Atmos. Meas. Tech. Discuss.: 16 June 2015

Revised: 15 September 2015 - Accepted: 29 September 2015 - Published: 15 October 2015

\begin{abstract}
In recent updates of the HITRAN water vapour $\mathrm{H}_{2} \mathrm{O}$ spectroscopic compilation covering the blue spectral region (here: $394-480 \mathrm{~nm}$ ) significant changes for the absorption bands at 416 and $426 \mathrm{~nm}$ were reported. In order to investigate the consistency of the different cross-sections calculated from these compilations, $\mathrm{H}_{2} \mathrm{O}$ vapour column density ratios for different spectral intervals were retrieved from long-path and multi-axis differential optical absorption spectroscopy (DOAS) measurements. We observed a significant improvement of the DOAS evaluation when using the updated HITRAN water vapour absorption cross-sections for the calculation of the reference spectra. In particular the magnitudes of the residual spectra as well as the fit errors were reduced.

However, we also found that the best match between measurement and model is reached when the absorption crosssection of groups of lines are scaled by factors ranging from 0.5 to 1.9 , suggesting that the HITRAN water vapour absorption compilation still needs significant corrections. For this spectral region we present correction factors for HITRAN 2009, HITRAN 2012, HITEMP and BT2 derived from field measurements. Additionally, upper limits for water vapour absorption in the UV-A range from 330 to $390 \mathrm{~nm}$ are given.
\end{abstract}

\section{Introduction}

Precise knowledge of the atmospheric water vapour absorption not only is crucial to calculate Earth's radiation budget since water vapour is the largest contributor to the natural greenhouse effect (Myhre et al., 2013) but also needs to be known at high precision when retrieving other atmospheric absorbers from spectroscopic measurements in the UV/VIS wavelength range. If their absorptions overlap, this can lead to errors in measurements of several trace gases. Due to technical limitations and since the absorption cross-sections are small in the region below $500 \mathrm{~nm}$ (above $20000 \mathrm{~cm}^{-1}$ ), the body of available experimental data in this spectral interval is sparse. Numerous absorption lines in the blue spectral region included in absorption line databases like HITRAN 2009 (Rothman et al., 2009), HITRAN 2012 (Rothman et al., 2013) and HITEMP (Rothman et al., 2010) are therefore based on theoretical calculations only. According to Tennyson et al. (2013) and references therein, validation measurements of individual water absorption lines are only available at wavelengths longer than $394.7 \mathrm{~nm}\left(25337 \mathrm{~cm}^{-1}\right)$, but a large fraction of the absorption lines included in the databases in this region is not validated by measurements.

More recently, water vapour absorption was also observed (Maksyutenko et al., 2012) and modelled (Polyansky et al., 2012) in the UV range below $370 \mathrm{~nm}$. The HITEMP absorption line database for $\mathrm{H}_{2} \mathrm{O}$ (Rothman et al., 2010) relies to a large extent on the ab initio line list BT2 calculated by Barber et al. (2006). Including the BT2 data increased the number of absorption lines especially in the blue wavelength region drastically: from 410 to $434 \mathrm{~nm}$ (W1 + W2, see Table 5) HITRAN 2009 contains 20 absorption lines with in- 


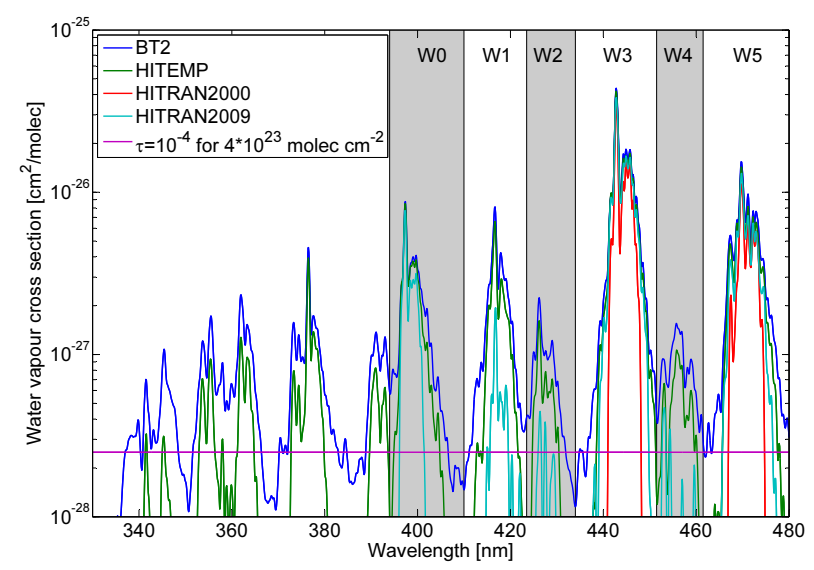

Figure 1. Overview of a subset of published water vapour absorption cross-sections convolved to a spectral resolution of $0.5 \mathrm{~nm}$. Also indicated is a typical line detection limit for a differential OD of $10^{-4}$ at a water vapour column density of $4 \times 10^{23}$ molec cm $\mathrm{cm}^{-2}$ (purple line) at a spectral resolution of $0.5 \mathrm{~nm}$. The wavelength intervals W0-W5 are described in the text; integrated absorptions in these intervals are given in Table 3.

tensities above $10^{-27} \mathrm{~cm} \mathrm{molec}^{-1}$ at room temperature, and HITEMP and BT2 contain 382 individual absorption lines. Ratios of absorption line intensities from BT2 and HITEMP are found between 0.5 and 3, because experimental data included in HITRAN 2009 were only combined with the BT2 data when certain criteria were met, as described in Rothman et al. (2010). An overview of the cross-sections from HITRAN 2009, HITEMP and BT2 is shown in Fig. 1. Convolved to a resolution of $0.5 \mathrm{~nm}$, the differences between the HITRAN 2012 cross-section and the HITEMP cross-section are negligible; therefore they are treated as equivalent here.

The vibrational state of the triatomic asymmetric top water molecule can be described in standard normal mode notation by three quantum numbers: $v_{1}$ (symmetric stretch), $v_{2}$ (bend) and $v_{3}$ (asymmetric stretch). The water vapour absorption shown in Fig. 1 has its structure due to the closeness of the numerous interacting vibrational states. These absorption structures can be named using a convention described in (Tennyson et al., 2001): a polyad is given a label $\mathrm{n} v$, where $\mathrm{n}$ is $v_{1}+v_{2} / 2+v_{3}$ for even $v_{2}$ and $\mathrm{n} v+\delta$ for odd $v_{2}$.

A widely used approach to measure trace gases in the atmosphere of the Earth is the technique of differential optical absorption spectroscopy (DOAS) (Platt and Stutz, 2008). Typically, absorption spectra covering $100-200 \mathrm{~nm}$ sections in the UV or visible spectral range are recorded by a grating spectrometer at a spectral resolution of $0.3-1 \mathrm{~nm}$. Suitable evaluation of differential absorption structures allows quantitative determination of column densities and concentrations of numerous trace gas species, even if their spectral features overlap. This allows for simultaneous evaluation of several trace gases in the atmosphere at high temporal resolution.
Absorption path lengths for different DOAS setups range from several hundreds of metres to several tens of kilometres in the free troposphere. Optical densities (ODs) can often be resolved down to $1 \times 10^{-4}$ (e.g. Platt and Stutz, 2008; Coburn et al., 2011), which in turn means that water absorption lines can be observed up to an accuracy of $5 \times 10^{-28} \mathrm{~cm}^{2} \mathrm{molec}^{-1}$ at a resolution of typically $0.5 \mathrm{~nm}$ when other absorbers in the respective spectral region are well known and/or their total absorptions are small.

While absorption structures due to known absorbers can be readily disentangled, problems can arise from unknown spectral features. One example - as mentioned above - is the uncertainty of the weak absorption features of water vapour in the blue spectral region.

Frequently the actual water vapour content during the measurements is not of primary interest, but nevertheless water needs to be corrected for when evaluating the absorption spectra. For example, weak water absorptions can be found in the typical evaluation range of iodine monoxide (ca. $414-440 \mathrm{~nm}$ ). Iodine monoxide (IO) plays a role in atmospheric chemistry and creation of cloud condensation nuclei. Elevated IO levels can be found in coastal areas (e.g. Seitz et al., 2010) as well as on the open ocean (e.g. Read et al., 2008; Großmann et al., 2013), in the free troposphere (e.g. Dix et al., 2013) and in polar regions (e.g. Frieß et al., 2010; Schönhardt et al., 2012). For a typical tropospheric water vapour slant column density (SCD) found in moderate climate of $S_{\mathrm{H}_{2} \mathrm{O}}=4 \times 10^{23}$ molec cm${ }^{-2}$ the resulting optical density is $2.5 \times 10^{-3}$ (when taking the cross-section data from HITEMP) at a spectral resolution of $0.5 \mathrm{~nm}$. Optical densities due to IO in the tropical marine boundary layer are 5 times weaker, i.e. of the order of $4 \times 10^{-4}$; thus to avoid possible errors in the retrieval of IO due to incomplete correction of the water vapour absorption, precise knowledge of the water vapour absorption cross-section is essential. Older versions of HITRAN such as HITRAN 2000 did not even include any absorptions in this spectral range.

Even more important is the correction of water vapour absorptions for the retrieval of glyoxal (e.g. Sinreich et al., 2010; Mahajan et al., 2014, and references therein), which can be evaluated in the spectral range from 432 to $458 \mathrm{~nm}$. For a typical tropospheric water vapour SCD $S_{\mathrm{H}_{2} \mathrm{O}}=4 \times$ $10^{23} \mathrm{molec} \mathrm{cm}^{-2}$ the resulting OD is $1.7 \times 10^{-2}$ in this wavelength range at a spectral resolution of $0.5 \mathrm{~nm}$, while the typical glyoxal differential slant column densities (dSCDs) as reported by Sinreich et al. (2010) for the marine boundary layer of $1.5 \times 10^{15} \mathrm{molec} \mathrm{cm}^{-2}$ correspond to $8 \times 10^{-4}$ and thus is 10 times weaker than the water vapour absorption. Moreover, the main spectral absorption features of water vapour and glyoxal overlap in some parts, potentially introducing crosssensitivities and/or increasing the measurement error. At the spectral region of maximum absorption of glyoxal the difference between the water vapour absorption cross-sections found in HITRAN 2000 and HITEMP for a typical SCD $S_{\mathrm{H}_{2} \mathrm{O}}=4 \times 10^{23}$ molec cm $^{-2}$ is about $4 \times 10^{-4}$ and amounts 
to one-half of the reported glyoxal absorption. Recently the accuracy of glyoxal measurements by CE-DOAS and MAXDOAS was estimated from chamber measurements by Thalman et al. (2015) and field measurements by Volkamer et al. (2015). For their instruments, water vapour absorption can explain an uncertainty of 5 pptv glyoxal (Volkamer et al., 2015) and less than 15 pptv glyoxal (Thalman et al., 2015).

Water vapour absorption can also have an impact on the spectral retrieval of the oxygen dimer $\mathrm{O}_{4}$ (also called $\mathrm{O}_{2}-\mathrm{O}_{2}$ ) around $477 \mathrm{~nm}$. Its column densities can be used to constrain radiative transfer simulations in remote sensing application and to obtain height profile information of aerosol extinction and trace gas concentrations (e.g. Frieß et al., 2006).

Water vapour column densities have been measured in the blue wavelength range from satellite (Wagner et al., 2013b; Wang et al., 2014) as well as from ground-based instruments (Wagner et al., 2013a). Here the $7 v$ absorption at $442 \mathrm{~nm}$ from HITRAN 2004 has been used for retrieving the atmospheric water vapour column density. These measurements require precise water vapour absorption cross-sections as well to minimise retrieval errors.

If significant absorptions of water vapour were present below $370 \mathrm{~nm}$, these could have an effect on the spectral evaluation of measurements of e.g. $\mathrm{BrO}, \mathrm{HCHO}, \mathrm{HONO}, \mathrm{SO}_{2}$ and $\mathrm{O}_{4}$. Based on currently available cross-section data, no atmospheric water vapour absorptions in this spectral range have been reported for DOAS measurements so far.

\section{Measurement campaigns}

The data analysed here were collected during two field campaigns (see Table 1) in which different instruments were used. The DOAS measurements during both campaigns, research cruise SOPRAN M91 off the coast of Peru and Halo$\mathrm{CaVe}$ on Cape Verde, aimed to quantify the abundance of reactive trace gases, especially $\mathrm{IO}$ and $\mathrm{BrO}$, in the marine boundary layer. HaloCaVe took place parallel to SOPRAN cruise P399 (Bange, 2011) on RV Poseidon in the Mauritanian upwelling region (Hepach et al., 2014). The absorption of IO is overlayed by water vapour absorption. Therefore proper water vapour correction in the spectral retrieval of IO is crucial to obtain reliable measurements of IO. SOPRAN is embedded in the international Surface Ocean - Lower Atmosphere Study (SOLAS) project.

1. During the SOPRAN cruise M91 with the research vessel Meteor multi-axis (MAX)-DOAS data were collected in the Peruvian upwelling region in December 2012 (Bange, 2013)

2. Long-path (LP)-DOAS measurements were analysed for water vapour using data from the intensive campaign HaloCaVe within SOPRAN at the Cape Verde Atmospheric Observatory (CVAO, Carpenter et al., 2010) during summer and fall 2010.
Table 1. Information about the campaigns from which measurement data were used.

\begin{tabular}{lll}
\hline Name & Type & Location, time \\
\hline M91 & MAX-DOAS & Peru, coastal upwelling, \\
& & $5^{\circ} \mathrm{S} 82^{\circ} \mathrm{W}-16^{\circ} \mathrm{S} 75^{\circ} \mathrm{W}$, \\
& & $1-25$ December 2012 \\
\hline HaloCaVe & LP-DOAS & $\mathrm{CVAO}$, \\
& & $16^{\circ} 52^{\prime} \mathrm{N} 24^{\circ} 52^{\prime} \mathrm{W}$, \\
& & June-October 2010 \\
\hline
\end{tabular}

The sites of both campaigns were located far away from any strong anthropogenic pollution; thus interferences due to e.g. high $\mathrm{NO}_{2}$ mixing ratios on the data evaluation should be negligible.

\section{The DOAS method}

The DOAS method (Platt and Stutz, 2008) relies on attenuation of light from suitable light sources by absorbers within the light path according to Lambert-Beer's law $I(\lambda)=$ $I_{0}(\lambda) \exp (-\tau(\lambda))$.

The optical density $\tau(\lambda)$ is calculated from a reference spectrum, $I_{0}(\lambda)$, and a measurement spectrum, $I(\lambda), \tau(\lambda)=$ $-\ln \frac{I(\lambda)}{I_{0}(\lambda)}$. In order to remove broad-band Mie and Rayleigh extinction, the OD is subdivided into a narrow-band (differential) and a broad-band part, $\tau(\lambda)=\tau_{\mathrm{B}}(\lambda)+\tau_{\mathrm{d}}(\lambda) \cdot \tau_{\mathrm{d}}(\lambda)$ is expressed by a sum of the differential parts of possible absorbers with their differential absorption cross-sections $\sigma_{\mathrm{d}, i}(\lambda)$ and concentrations $c_{i}$ of absorber (i.e. trace gas) $i$.

$\tau_{\mathrm{d}}(\lambda)=L \sum_{i} c_{i} \sigma_{\mathrm{d}, i}(\lambda)$

The column density $S_{i}=L \times c_{i}$ of the trace gas $i$ (with the concentration $c_{i}$ ) is calculated by a fitting routine, which is applied to data from a wavelength interval with a width of several nanometres to several tens of nanometres. The absorption path $L$ is known for LP-DOAS measurements and can be estimated or calculated from radiative transfer models for MAX-DOAS measurements. The high-resolution literature cross-sections $\sigma_{\mathrm{L}, i}$ are convolved with the instrument function $H$ of the respective setup to obtain $\sigma_{i}=H \otimes \sigma_{\mathrm{L}, i}$, the absorption cross-section as it would be determined by the instrument. In an analogous fashion to the optical density, cross-sections can also be subdivided into a broadband and narrow-band (differential) contribution: $\sigma_{i}=\sigma_{\mathrm{B}, i}+\sigma_{\mathrm{d}, i}$. The instrument function $\mathrm{H}$ is usually measured by observing individual atomic emission lines of mercury, which have a width which is 2 orders of magnitude smaller than the resolution of the instrument (Sansonetti et al., 1996). Corrections to this simple convolution procedure are discussed in Sect. 4.4. 


\subsection{MAX-DOAS measurements}

The method of MAX-DOAS measurements was first described by Hönninger and Platt (2002) and uses scattered sunlight collected by a telescope pointing towards the sky at different elevation angles. Each elevation angle has a different sensitivity for absorptions in different heights of the atmosphere. Low elevation angles have a higher sensitivity to absorbers close to the surface, because the additional light path compared to a zenith spectrum is mostly located within the lowermost layers of the atmosphere (Hönninger et al., 2004).

The SCD is defined as the integral over the concentration $\rho$ along the light path $L$ and is hence given in units of molecules $\mathrm{cm}^{-2}$. In equations we abbreviate it with $S$.

$S=\int_{L} \rho(s) \mathrm{d} s$

From the MAX-DOAS measurements dSCDs $\Delta S$ can be calculated for each fitted trace gas: a Fraunhofer reference spectrum $I_{0}(\lambda)$ is chosen from one of the measurement spectra and the dSCD $\Delta S(\alpha)=S(\alpha)-S_{\text {ref }}$ is obtained from the DOAS fit for each elevation angle $\alpha$ relative to the Fraunhofer reference. Typically, a zenith spectrum is taken as reference and thus $S_{\text {ref }}=S\left(90^{\circ}\right)$. In the measurements reported here, the DOAS fit includes the convolved cross-sections listed in Table 2. In addition, Ring spectra are fitted (see Table 2), which serve to compensate for the effect of rotational Raman scattering. The influence of vibrational Raman scattering (VRS) of $\mathrm{N}_{2}$ and $\mathrm{O}_{2}$ as described in Lampel et al. (2015) on the obtained results listed in Table 5 was not found to be significant. As also described in Lampel et al. (2015), no significant contribution to observed ODs by VRS of liquid water (Vountas et al., 2003; Peters et al., 2014) was found most likely due to turbid water and consequently short light paths under water. VRS of water vapour itself is expected to result in an intensity offset and in differential structures especially at 459 and $463 \mathrm{~nm}$, as it red shifts the solar spectrum by $\approx 3654 \mathrm{~cm}^{-1}$ (Penney and Lapp, 1976; Murphy, 1978; Rizi et al., 2004). However, its expected magnitude $\left(<5 \times 10^{-5}\right)$ is below the typical magnitudes of residual spectra. Its spectral signature was not found in these MAX-DOAS measurements.

By choosing references recorded shortly before or after the measurement spectrum, the influence of the instrumental instabilities on the result was minimised and the influence of stratospheric absorbers was largely cancelled out (see e.g. Hönninger and Platt, 2002). In order to avoid measurements in which direct sunlight might have entered the telescope at $90^{\circ}$ elevation in the southern part of the cruise track, spectra at $40^{\circ}$ are used as reference spectra.

A description of the instrument operated during the SOPRAN cruise M91 can be found in Großmann et al. (2013). The optical resolution of the instrument during this campaign
Table 2. The cross-sections that were used for the spectral retrieval. All shift and squeeze parameters of the cross-sections were linked to each other, while those of Ring, measurement and reference spectra were linked separately.

\begin{tabular}{|c|c|}
\hline Absorber & Source \\
\hline $\mathrm{NO}_{2} 294 \mathrm{~K}$ & Vandaele et al. (1998) (MAX-DOAS) \\
\hline $\mathrm{NO}_{2} 294 \mathrm{~K}$ & Vandaele et al. (2002) (LP-DOAS) \\
\hline $\mathrm{O}_{3} 223 \mathrm{~K}$ & Serdyuchenko et al. (2014) \\
\hline $\mathrm{O}_{4} 293 \mathrm{~K}$ & Thalman and Volkamer (2013) \\
\hline IO & Spietz et al. (2005) \\
\hline Glyoxal & Volkamer et al. (2005) (for tests only) \\
\hline Polynomial & third order \\
\hline \multicolumn{2}{|l|}{ MAX-DOAS only: } \\
\hline Ring & $\begin{array}{l}\text { DOASIS, Kraus (2006) } \\
\text { and Bussemer (1993) }\end{array}$ \\
\hline Ring $\times \lambda^{4}$ & Wagner et al. (2009) \\
\hline Add. polynomial & zeroth order \\
\hline \multicolumn{2}{|l|}{ MAX-DOAS UV only: } \\
\hline $\mathrm{BrO}$ & Fleischmann (2004) \\
\hline $\mathrm{HCHO}$ & Chance and Orphal (2011) \\
\hline $\mathrm{NO}_{2} 223 \mathrm{~K}$ & Vandaele et al. (1998) \\
\hline $\mathrm{O}_{3} 246 \mathrm{~K}$ & Serdyuchenko et al. (2014) \\
\hline
\end{tabular}

was $0.45 \mathrm{~nm}$ and it covered a spectral range from 324 to $467 \mathrm{~nm}$.

The spectra used here were recorded for $1 \mathrm{~min}$ each at eight elevation angles of $90^{\circ}$ (zenith), 40, 20, 10, 6, 4, 2 and $1^{\circ}$ as long as solar zenith angles (SZAs) were $\leq 85^{\circ}$. The exposure time was adjusted to have spectra at a typical saturation of $50 \%$.

\subsection{LP-DOAS Measurements}

LP-DOAS instruments are based on an artificial light source, typically a xenon lamp or a light-emitting diode, retro reflectors, a telescope and a spectrometer. The light is sent with a telescope across the measurement distance to a retro reflector, which reflects the light back onto the same telescope. It collects the received light and transfers it to a spectrograph. A sequence of background measurements, light-source spectrum measurements without absorption and actual measurement spectra is used to ensure independence of the measured spectra from external sunlight and instrumental instabilities. The LP-DOAS setup has the advantage that the actual light path is well defined and thus concentrations of molecules can be directly derived,; also, measurements at night are possible.

The optical density $\tau(\lambda)$ is calculated from a background corrected light source spectrum and a background corrected atmospheric spectrum and filtered by a binomial high-pass with 1000 iterations. The convolved and high-pass filtered literature cross-sections listed in Table 2 are then fitted to the corrected OD.

A description of the LP-DOAS instrument can be found in Pöhler et al. (2010). The light path used for the measurements 
Table 3. Integrated absorption in $\left[10^{-27} \mathrm{~nm} \mathrm{~cm}^{2}\right]$ over each of the wavelength intervals W0-W5 for different sources of cross-section data. Not only are W3 variations (reference measurements, bold face) between the different compilations seen for the largest absorption structure but relative integrated absorption values also vary. The last row shows the maximum optical density for a water vapour column density (CD) $\mathrm{S}=4 \times 10^{23}$ molec $\mathrm{cm}^{-2}$ within each wavelength interval at a spectral resolution of $0.5 \mathrm{~nm}$.

\begin{tabular}{lcrrrrrr}
\hline $\begin{array}{l}\text { Dominating polyad } \\
\text { Name }\end{array}$ & & $\begin{array}{r}8 v \\
\text { W0 }\end{array}$ & W1 & W2 & $\begin{array}{r}7 v \\
\text { W3 }\end{array}$ & W4 & $\begin{array}{r}6 v+\delta \\
\text { W5 }\end{array}$ \\
\hline Start of interval & $(\mathrm{nm})$ & 394.0 & 410.0 & 423.5 & $\mathbf{4 3 4 . 0}$ & 451.5 & 461.5 \\
End of interval & $(\mathrm{nm})$ & 410.0 & 423.5 & 434.0 & $\mathbf{4 5 1 . 5}$ & 461.5 & 480.0 \\
\hline Source of cross-section data & & \multicolumn{7}{c}{ integrated cross-section } \\
\hline HITRAN 2000 & {$\left[10^{-27} \mathrm{~nm} \mathrm{~cm}^{2}\right]$} & 0.00 & 0.00 & 0.00 & $\mathbf{6 9 . 0 2}$ & 0.00 & 31.03 \\
HITRAN 2004 & & 13.62 & 3.11 & 0.89 & $\mathbf{9 6 . 7 5}$ & 0.87 & 42.25 \\
HITRAN 2009 & & 13.71 & 3.13 & 0.90 & $\mathbf{9 7 . 0 7}$ & 0.88 & 42.46 \\
HITEMP & & 21.01 & 15.73 & 4.01 & $\mathbf{1 0 6 . 9 0}$ & 4.50 & 51.44 \\
BT2 & & 26.05 & 23.84 & 7.86 & $\mathbf{1 1 6 . 5 0}$ & 8.46 & 62.67 \\
\hline OD HITEMP for $\mathrm{CD}=4 \times 10^{23} \mathrm{molec} \mathrm{cm}^{-2}$ & {$\left[10^{-4}\right]$} & 36 & 27 & 6 & $\mathbf{1 6 5}$ & 4.5 & 62 \\
\hline
\end{tabular}

reported was $12.64 \mathrm{~km}$ long, similar to the one in Read et al. (2008). The spectral resolution was $0.5 \mathrm{~nm}$.

To exclude the possibility of interferences with daylight, only spectra at a solar zenith angle of more than $90^{\circ}$ (nighttime) are reported here.

\subsection{Spectral retrieval}

The $\mathrm{H}_{2} \mathrm{O}$ cross-sections were calculated using modelled line widths according to Kuntz (1997) from the respective compilation or line list using an extraction program by Christian Frankenberg (Frankenberg, 2005) with a spectral resolution of $1 \mathrm{pm}$ for an ambient temperature of $298 \mathrm{~K}$ and $1013 \mathrm{hPa} .{ }^{1}$ For the BT2 data set, a cross-section file from the ExoMol project (Tennyson and Yurchenko, 2012) ${ }^{2}$ was downloaded; here only Doppler line broadening effects were considered (Hill et al., 2013). Variations of temperature and pressure within the range of atmospheric measurements were found not to have a significant effect on our measurements in the blue wavelength region as the bulk of the absorption by water vapour molecules takes place within the boundary layer.

The choice of cross-section to compensate for absorption of the oxygen dimer $\mathrm{O}_{4}$ did not significantly affect the overall result. We tested cross-sections from Hermans et al. (1999), Thalman and Volkamer (2013) and Greenblatt et al. (1990).

The spectral window of this study for MAX-DOAS measurements was limited at the lower end to $398 \mathrm{~nm}$ to avoid a strong influence of the Ring effect caused by rotational Raman scattering (Shefov, 1959; Grainger and Ring, 1962). The

\footnotetext{
${ }^{1}$ The HITRAN 2009, HITEMP and HITRAN 2012 data used here were downloaded from the HITRAN website (http://www.cfa. harvard.edu/hitran/) with the file name "01 hit09.par", HITEMP "01 hitemp.par" and HITRAN 2012 "01 hit12.par".

${ }^{2} \mathrm{http} / / / \mathrm{www}$. exomol.com/xsecs/1H2-16O
}

upper bound (at $461.5 \mathrm{~nm}$ ) was chosen due to instrumental limitations.

The water vapour absorption cross-section was divided into six spectral regions, W0-W5, before convolution, as listed in Table 3. All other absorbers (Table 2) were fitted normally. An example fit can be seen in Fig. 2.

In the literature, significant absorption structures due to glyoxal in the eastern Pacific region were reported by Sinreich et al. (2010). However, during our cruise no absorption due to glyoxal was found to exceed our detection limit of $2 \sigma=5 \times 10^{14} \mathrm{molec} \mathrm{cm}^{-2}$ glyoxal at low elevation angles of $1-3^{\circ}$ relative to $40^{\circ}$. This detection limit was determined after analysing the spectral data in a fit window from 432 to $460 \mathrm{~nm}$. The upper limit was independent of the choice of literature $\mathrm{O}_{4}$ absorption cross-section and independent of the choice of water vapour cross-section (tested for HITRAN2009, HITEMP and BT2). Furthermore, it was not exceeded when including a correction spectrum for VRS of liquid water, liquid water absorption, VRS of air or a correction spectrum to account the changes of the effective water vapour absorption band shape introduced by radiative transfer effects in strong water vapour absorption lines around $442 \mathrm{~nm}$. The result remained the same for different fit windows.

To avoid problems in situations with low light intensity, we used only data in which the signal was sufficiently high to provide a RMS noise of the residual spectrum below $4 \times$ $10^{-4}$.

\subsubsection{Radiative transfer effects (MAX-DOAS)}

The light path of the LP-DOAS measurement is well defined and constant. Thus measurements of the different W0-W5 column densities can be directly used. However, the effective light path of MAX-DOAS measurements is not known and 


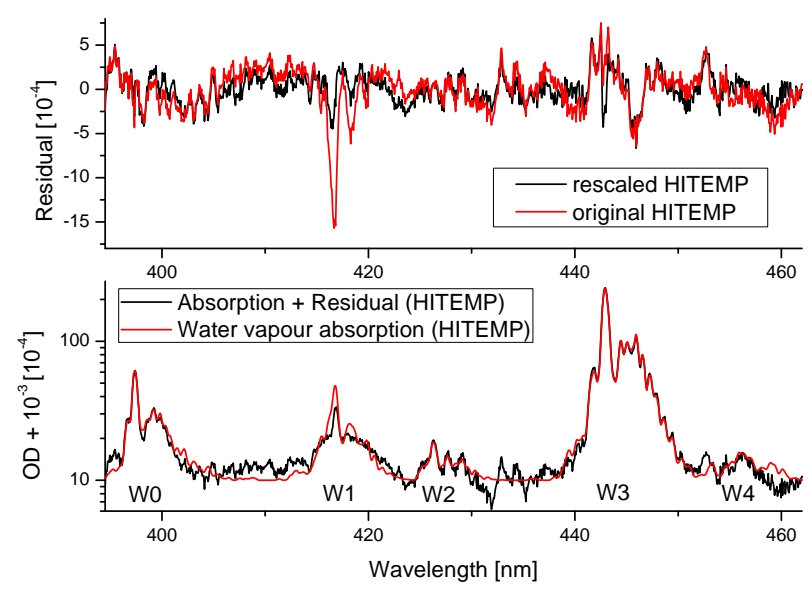

Figure 2. Fit residuals (top panel) and water vapour OD (bottom) for a MAX-DOAS observation using the HITEMP cross-section. A residual from an individual fit using the original HITEMP crosssection and a fit using separate column densities for each of the absorption structures in the windows W0-W4 from HITEMP is shown in the top panel. From all fits with separate column densities for the absorption bands, correlation plots with respect to W3 were performed as shown exemplary in Fig. 3. The results are listed in Table 5 . The overall water vapour column density calculated from the data shown above is $\mathrm{dSCD}=5.31 \times 10^{23}$ molec cm $^{-2}$.

depends on several factors: wavelength, aerosol and trace gas profiles, viewing direction, position of the Sun, etc.

The radiative transfer for the measurements was simulated using McArtim (Deutschmann et al., 2011) in order to estimate the effect of radiative transfer at different wavelengths. We did not aim for full profile inversion for aerosol extinction profiles and water vapour, as the correlation for the complete data set e.g. as shown in Fig. 3 is good and no strong dependence of individual measurements on viewing geometry is observed.

Water vapour dSCDs in the atmosphere were simulated at different wavelengths to estimate the effect of radiative transfer on the relative observed absorption band strengths for MAX-DOAS measurements. Since the data were taken from a measurement period of a whole month, a representative water vapour profile was used with a surface mixing ratio of $2.3 \%$ and linearly decreasing to $0 \%$ at a height of $6 \mathrm{~km}$ (similarly as in Bleisch and Kampfer, 2012, and radiosonde profiles by Fuhlbrügge et al., 2015). This is similar to Wagner et al. (2013a), who found scale heights around $2 \mathrm{~km}$ for the water vapour profile. The absolute humidity of air close to the sea surface was between 1.6 and $2.4 \%$ according to the meteorological data recorded onboard the research vessel. An exponentially decreasing aerosol profile with an aerosol optical thickness (AOT) of 0.22 at $360 \mathrm{~nm}$ was used for the simulations. The AOT is within the range of the values observed on RV Meteor during M77 in 2008 in the same region listed in the AERONET MAN database by Smirnov et al. (2009). It is in agreement with aerosol profile retrievals during clear days
Table 4. Corrections of the effective light path according to radiative transfer modelling for the MAX-DOAS measurements. The reference measurements, W3, are in bold.

\begin{tabular}{lcccccc}
\hline & W0 & W1 & W2 & W3 & W4 & W5 \\
\hline Wavelength $(\mathrm{nm})$ & 400 & 416 & 424 & $\mathbf{4 4 2}$ & 455 & 460 \\
\hline McArtim & 0.93 & 0.96 & 0.98 & $\mathbf{1 . 0 0}$ & 1.02 & 1.04 \\
SD & 0.02 & 0.02 & 0.01 & - & 0.02 & 0.02 \\
\hline
\end{tabular}

based on $\mathrm{O}_{4}$ dSCDs at $360 \mathrm{~nm}$ following the optimal estimation approach described in Frieß et al. (2006) and Yilmaz (2012).

The results were averaged over a range of SZAs of 10$80^{\circ}$ representing the used MAX-DOAS data and over all encountered relative solar azimuth angles. The standard deviation listed in Table 4 reflects the variations in simulated $\mathrm{H}_{2} \mathrm{O}$ dSCDs due to varying observation geometries.

The magnitude of the resulting water vapour dSCDs obtained from the model agreed with the MAX-DOAS observations. McArtim allows calculating the wavelength dependence of the simulated water vapour dSCDs. The scatter in the correlations for the water absorption bands (Fig. 3) will then already include the scatter caused by different measuring geometries, which means that the observed differences in relative strengths of the absorptions especially for $\mathrm{W} 1$ and W2 are significant. However, the correction obtained from radiative transfer calculations (shown in Table 4) needs to be applied to MAX-DOAS observations to match the LPDOAS results. The correction of the wavelength dependence reduces the discrepancy of MAX-DOAS and LP-DOAS measurements e.g. for W0 when using HITEMP and BT2. The wavelength-corrected results are listed in Table 5.

It is a well-known effect (see e.g. Platt et al., 1997) that strong absorbers influence the light path length in the atmosphere and thus the air mass factor. The change of the air mass factor within a water vapour absorption band due to the highly resolved water vapour optical density in the region $<480 \mathrm{~nm}$ was found to be insignificant. Deviations of less than $2 \%$ on the values listed in Table 5 were observed.

However, if the focus is on weak absorbers being overlayed by strong water vapour absorptions, a correction for the change of air mass factors by strong absorption is necessary to avoid water vapour OD-correlated structures in the residual spectra and effects on the retrieval of other absorbers.

\section{Results}

The water vapour dSCDs derived in different spectral regions of the same measured spectra were compared to each other. In principle the same water vapour dSCD values are expected, but significant differences were found. 
Table 5. Measured relative line strengths for the different cross-sections with respect to the absorption at W3 (see Fig. 1 and Table 3 ), which is the reference column in bold face. Errors obtained from the linear regression are shown for the last digits in brackets. The relative DOAS fit errors are listed in Table 6. Results with typical DOAS fit errors of more than $25 \%$ of the measured values were put in square brackets. MAX-DOAS values are corrected by the results of radiative transfer modelling listed in Table 4.

\begin{tabular}{llllllll}
\hline $\begin{array}{l}\text { Dominating polyad } \\
\text { Name }\end{array}$ & & $\begin{array}{l}8 v \\
\mathrm{~W} 0\end{array}$ & $\begin{array}{l}7 v+\delta \\
\mathrm{W} 1\end{array}$ & $\mathrm{~W} 2$ & $\begin{array}{l}7 v \\
\text { W3 }\end{array}$ & W4 & $\begin{array}{l}6 v+\delta \\
\text { W5 }\end{array}$ \\
\hline Start of interval & $(\mathrm{nm})$ & 394.0 & 410.0 & 423.5 & $\mathbf{4 3 4 . 0}$ & 451.5 & 461.5 \\
End of interval & $(\mathrm{nm})$ & 410.0 & 423.5 & 434.0 & $\mathbf{4 5 1 . 5}$ & 461.5 & 480.0 \\
\hline Source of cross-section data & DOAS & & & & & & \\
\hline HITRAN 2009 & MAX & $1.0875(5)$ & $1.9497(14)$ & {$[1.6862(46)]$} & $\mathbf{1}$ & {$[0.3115(51)]$} & \\
& LP & $1.02(2)$ & $0.99(6)$ & {$[1.6(2)]$} & $\mathbf{1}$ & {$[0.7(3)]$} & $1.02(1)$ \\
\hline HITEMP & MAX & $1.0201(4)$ & $0.6578(4)$ & $0.769(2)$ & $\mathbf{1}$ & $0.360(2)$ & - \\
& LP & $1.17(2)$ & $0.42(2)$ & {$[0.91(8)]$} & $\mathbf{1}$ & {$[1.33(13)]$} & $1.03(1)$ \\
\hline HITEMP & MAX & $1.0182(4)$ & $0.6534(4)$ & $0.744(2)$ & $\mathbf{1}$ & $0.359(2)$ & - \\
(with glyoxal) & LP & & & & & & \\
\hline BT2 & MAX & $1.0108(4)$ & $0.5183(3)$ & $0.546(1)$ & $\mathbf{1}$ & $0.395(1)$ & - \\
& LP & $1.19(2)$ & $0.37(2)$ & {$[0.74(8)]$} & $\mathbf{1}$ & {$[1.01(12)]$} & $1.01(1)$ \\
\hline
\end{tabular}

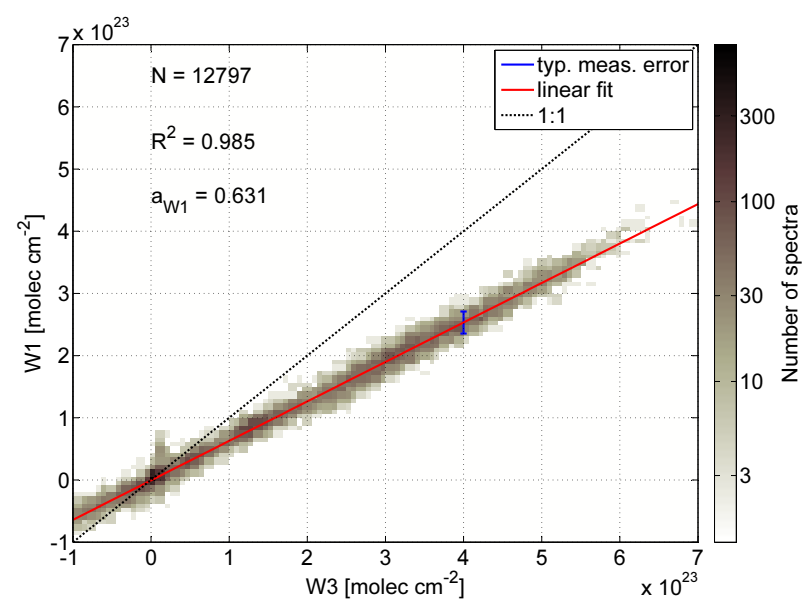

Figure 3. Correlation of dSCD in molec $\mathrm{cm}^{-2}$ calculated for $\mathrm{W} 1$ $(7 v+\delta$ polyad) and W3 (7v polyad) from MAX-DOAS (M91) data using the HITEMP cross-section. The blue error bar (at $\mathrm{S}_{\mathrm{W} 3}=4 \times 10^{23}$ molec $\mathrm{cm}^{-2}$ ) indicates a typical measurement error. The convolved cross-section derived from the HITEMP compilation shows a maximum absorption cross-section of an individual absorption line in $5.9 \times 10^{26} \mathrm{~cm}^{-2}$ and $4.0 \times 10^{25} \mathrm{~cm}^{-2}$ for W1 and $\mathrm{W} 3$ respectively. The linear relationship of $\mathrm{W} 1$ and $\mathrm{W} 3$ dominates.

Values of the retrieved water vapour SCDs in different spectral intervals were compared to each other. Relative to the differential SCD of $\mathrm{W} 3 S_{\mathrm{W} 3}$, an error-weighted linear regression was done to obtain $a_{x}$ in $f\left(S_{x}\right)=a_{x} \times S_{\mathrm{W} 3} . a_{x}$ is the relative absorption strength of the interval $x$ relative to W3. The results are shown in Table 5. Typical DOAS fit errors for each cross-section in W0-W5 for individual measurements are summarised in Table 6 . In order to illustrate the differences, one of the data comparison plots with the relative absorption of W1 and W3 for HITEMP is shown in Fig. 3.

The weights for the linear regression were iteratively calculated according to Neri et al. (1989). A comparison with other methods for error-weighted linear regressions can be found in Cantrell (2008).

The water vapour absorption at $\approx 444 \mathrm{~nm}$ was used as a reference for the other absorption bands, because it is the strongest absorption in this spectral region (see Table 3).

The mathematical error from the regression is small compared to possible systematic errors, which might arise from the DOAS fit itself: its relative size is estimated by using twice the fit error given in Table 6 following the argumentation of Stutz and Platt (1996). These errors are then used to calculate the weighted mean deduced from MAX-DOAS and LP-DOAS observations for each of the absorption bands given in Table 5, when their respective relative fit error is smaller than $25 \%$.

In order to exclude an impact of glyoxal absorption on the evaluation of water vapour absorptions, the analysis procedure was repeated including glyoxal. The result is comparable to the result without glyoxal absorption, only the amplitude of the weak water absorption around $426 \mathrm{~nm}$ was slightly reduced by the additional degree of freedom introduced to the spectral retrieval.

For the LP-DOAS measurements an upper limit of $30 \mathrm{ppt}$ glyoxal (see also Mahajan et al., 2014) was determined and its cross-section was also not included in the final analysis.

Other MAX-DOAS observations in the same region showed larger glyoxal dSCDs (Sinreich et al., 2010), which was also detected at various other campaigns in the marine boundary layer as listed in Mahajan et al. (2014) and Volka- 
Table 6. Typical relative DOAS fit errors in fitting windows W0-W5 at a water vapour dSCD in W3 (bold) of $4 \times 10^{23} \mathrm{molec} \mathrm{cm}^{-2}$ for an individual spectrum integrated over $60 \mathrm{~s}$ (MAX-DOAS) and $280 \mathrm{~s}$ (averaged, LP-DOAS). Values are given in percent and are corrected by the relative sizes given in Table 5. For all weak absorption bands W1, W2 and W4 a reduction of fit errors is observed from HITRAN 2009 to HITEMP or BT2.

\begin{tabular}{llrrrrrr}
\hline (\%) & & W0 & W1 & W2 & W3 & W4 & W5 \\
\hline Start of interval & $(\mathrm{nm})$ & 394.0 & 410.0 & 423.5 & $\mathbf{4 3 4 . 0}$ & 451.5 & 461.5 \\
End of interval & $(\mathrm{nm})$ & 410.0 & 423.5 & 434.0 & $\mathbf{4 5 1 . 5}$ & 461.5 & 480.0 \\
\hline Source of cross-section data & & & & & & & \\
\hline \multirow{2}{*}{ HITRAN 2009 } & MAX-DOAS & 2.9 & 5.1 & 20 & $\mathbf{0 . 6 3}$ & 130 & \\
& LP-DOAS & 5.2 & 21 & 41 & $\mathbf{1 . 0 4}$ & 132 & 3.6 \\
\hline \multirow{2}{*}{ HITEMP } & MAX-DOAS & 2.6 & 3.9 & 13 & $\mathbf{0 . 5 9}$ & 42 & - \\
& LP-DOAS & 4.7 & 16 & 28 & $\mathbf{0 . 9 8}$ & 32 & 3.4 \\
\hline \multirow{2}{*}{ BT2 } & MAX-DOAS & 3.7 & 5.4 & 17 & $\mathbf{0 . 8 5}$ & 33 & - \\
& LP-DOAS & 4.6 & 16 & 28 & $\mathbf{0 . 9 4}$ & 34 & 3.2 \\
\hline
\end{tabular}

mer et al. (2015). The detection limit found here is at the lower range of these observations. As we performed various sensitivity studies for this data set, which could not explain this difference, we assume that this difference could be due to natural variability. The bulk of the measurements published in Sinreich et al. (2010) was not as close to the coast as M91. The measurements by Volkamer et al. (2015) were done in a different region, even north of the equator, which additionally also shows typically larger sea surface temperatures (SSTs) than the data presented here (SST during M91: $14-22{ }^{\circ} \mathrm{C}$; Fuhlbrügge et al., 2015).

The impact on IO dSCDs of the rescaled water vapour absorption is small, as long as the main water vapour absorption feature W3 is not included in the fit interval, which is typically the case as (e.g. Großmann et al., 2013; Prados-Roman et al., 2015; Volkamer et al., 2015). The impact on the IO $\mathrm{dSCD}$ is found to be smaller than $1 \times 10^{12}$ molec $\mathrm{cm}^{-2}$ for a fit interval from 418 to $438 \mathrm{~nm}$.

\subsection{Different separation approaches}

Deriving water vapour dSCDs in different wavelength windows is an approach which yields direct information about the relative absorption strength of different absorption bands. The result can easily be applied to DOAS measurements.

However, as the different polyads described by different $n=v_{1}+v_{2} / 2+v_{3}$ for the vibrational states $\left(v_{1}, v_{2}, v_{3}\right)$ of the water molecule overlap in the blue wavelength region, a separation by polyad could yield further information.

In the upper panel of Fig. 4, the HITEMP line list was separated according to its polyads and convolved to a representative spectral resolution of $0.5 \mathrm{~nm}$. Absorption lines which are not assigned to vibrational quantum numbers in HITEMP and can therefore not be assigned to one of the polyads are labelled "NA" in this plot. These absorption lines alone amount to an OD of several $10^{-4}$ for a dSCD of $4 \times 10^{23}$ molec $\mathrm{cm}^{-2}$. Then the same separation was done for different values of $v_{2}$.

Using the same spectral retrieval for MAX-DOAS measurements as described in Sect. 3.3 but using now the polyads $6 v+\delta, 7 v, 7 v+\delta, 8 v$ and the list of not-assigned (NA) absorption lines instead of W0-W5 did not show a significant improvement of the residual of the fit (mean RMS with W0-W5: $(1.89 \pm 0.01) \times 10^{-4}$; mean RMS with polyads: $\left.(1.90 \pm 0.01) \times 10^{-4}\right)$. This could have been caused by the NA absorption lines, which might scale differently. Or the separation of the absorption bands according to $n$ is not representing the underlying problem. A further indication, that this is indeed the case is the fact that the scaling of W2 is typically not close to unity, but here it belongs to $7 v$, which is by definition "correct". The absorption lines of W2 belong formally to the $7 v$ polyad, but as their bend modes are mostly $v_{2}=0,2$, this difference might in fact drive the observed differences. The W1 absorptions, which are overestimated in HITEMP, consist mostly of $v_{2}=1,2$, as also shown in Fig. 4. As the $v_{2}=1$ absorption lines seem to be of correct size (as indicated by W5), the reason for the observed discrepancies might be connected to higher bend states with $v_{2} \geq 2$.

Table 7 shows that the scaling factor for the polyads is close to unity except for $7 v+\delta$. As different scaling factors for the $7 v$ and $7 v+\delta$ polyads and "NA" will lead to a different shape of the absorption band $\mathrm{W} 1$ around $416 \mathrm{~nm}$, this could explain the remaining residual structures shown in Fig. 2 when rescaling the whole absorption band W1. However, if the structure in $7 v$ at $416 \mathrm{~nm}$ is not correct, this could be partly compensated by $7 v+\delta$ polyad, which then appears to have an overestimated absorption cross-section, as it is the case here.

In the lower panel in Fig. 4, the HITEMP line list is separated according to bend values $\nu_{2}$. Here it is obvious why the absorption $\mathrm{W} 2$ was labelled $7 v$, as here $v_{2}=2$. In the same way as the polyads were evaluated, the result from this 
Table 7. Relative absorption strengths as listed in Table 5 for the separated $\mathrm{H}_{2} \mathrm{O}$ absorption cross-section according to the respective polyad shown in Fig. 4. Below the same procedure for the HITEMP line list separated by eigenvalues of the bend mode $v_{2}$. As in Table 6 the fit error is given in percent at a dSCD of $4 \times 10^{23}$ molec $\mathrm{cm}^{-2}$ of the $7 v$ and $v=0$ absorptions respectively. As the wavelength ranges are not as well defined as before, no corrections by the results of radiative transfer modelling listed in Table 4 were done.

\begin{tabular}{lllllll}
\hline Polyad & $8 v$ & $7 v+\delta$ & $7 v$ & $6 v+\delta$ & "NA" & \\
\hline HITEMP & $0.977(1)$ & $0.283(1)$ & 1 & $0.791(2)$ & $1.045(2)$ & \\
Fit error $(\%)$ & 5 & 19 & 1 & 8 & 10 & \\
\hline$v_{2}$ & 0 & 1 & 2 & 3 & 4 & $\geq 5$ and "NA" \\
\hline HITEMP & 1 & $0.583(2)$ & $0.427(3)$ & $0.306(4)$ & {$[0.675(2)]$} & $0.799(2)$ \\
Fit error $(\%)$ & 0.6 & 6 & 12 & 23 & 42 & 35 \\
\hline
\end{tabular}
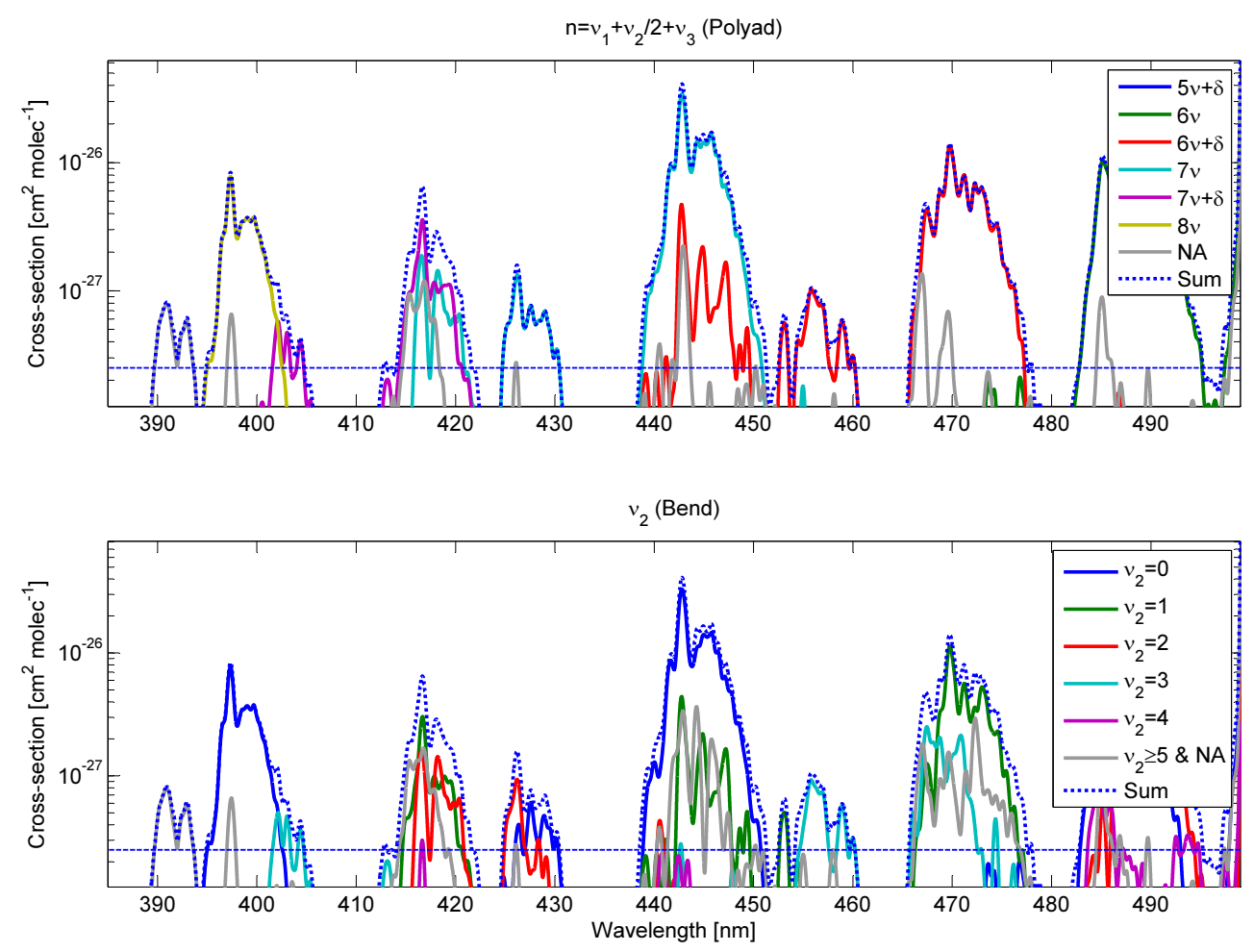

Figure 4. The HITEMP line list for water vapour separated according to polyads and bend mode: "NA" summarises all absorption lines which are listed with the vibrational quantum numbers $\left(v_{1}, v_{2}, v_{3}\right)=(-2,-2,-2)$ in HITEMP. The dotted horizontal line marks an OD of

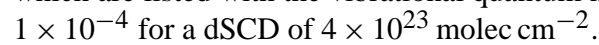

separation was also applied to the MAX-DOAS observations in order to see if this separation agrees better with observations. The results are listed in the lower part of Table 7, and a significant improvement of the RMS was not observed. The dominating $\nu_{2}=0-4$ values were separated and the remaining lines assigned to $v_{2}=5-9$ were combined with the NA absorption lines as also shown in Fig. 4.

The resulting scaling factors decrease with increasing values $v_{2}$ for the bend mode, which suggests that the observed discrepancies of relative absorption strength are caused mainly by higher values of $v_{2}$. The result for $v_{2}=4$ is close to the limit of detection.

\subsection{Comparison of LP-DOAS data with data from meteorological stations}

In order determine whether the assumed water vapour absorption cross-sections actually give the correct water vapour concentration, the main absorption W3 found in LP-DOAS data was compared to water vapour mixing ratios derived from meteorological parameters measured at the CVAO.

The meteorological station provides temperature, pressure and humidity data (Carpenter et al., 2010). This information was used to calculate the water vapour mixing ratio using the Magnus formula and to compare the result with LP-DOAS 


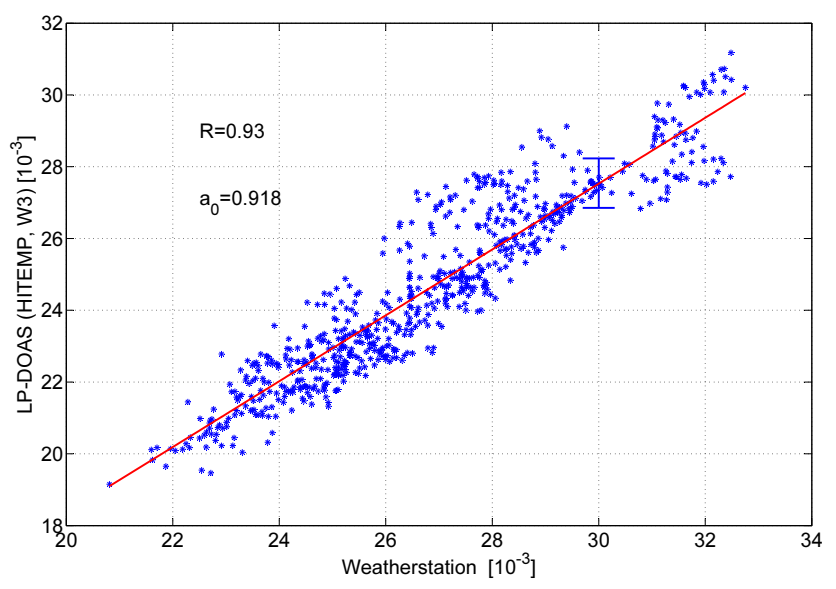

Figure 5. Comparison of LP-DOAS water vapour concentration with data from meteorological station at the CVAO. At 0.03 the error bar shows the mean measurement error of the LP-DOAS measurements, estimated by twice the DOAS fit error. The standard deviation of the residual of the linear fit is 2.5 times as large as the fit error.

data. Taking the measurement error given for the meteorological station, the stated error in the temperature measurements of $0.3{ }^{\circ} \mathrm{C}$ results in $2 \%$ uncertainty in the relative humidity. Pressure uncertainties cancel out, since the same pressure measurements were used for the conversion of column densities from LP-DOAS to mixing ratios as well as in the Magnus formula. An error of $5 \%$ in relative humidity directly translates in an $5 \%$ error for the mixing ratio. This means that the absolute differences of the cross-sections shown in Table 3 cannot be absolutely validated with sufficient precision, even though the water vapour mixing ratios ranged from 2.0 to $3.4 \%$ and meteorological station data and LP-DOAS water vapour data correlated with a Pearson's $R=0.93$ as shown in Fig. 5. Slope and offset values are listed in Table 8. The LP-DOAS results based on the HITEMP cross-section were on average $7 \%$ lower than the values inferred from the meteorological station data and thus closer to the absolute magnitude of the W3 absorption in HITRAN 2009. Retrieving tropospheric water vapour profiles from the MAX-DOAS measurements introduced even larger deviations probably due to uncertainties in retrieving the required aerosol profiles.

\subsection{Absorption of water vapour in the UV wavelength range}

As mentioned above, water vapour absorptions are observed not only in the spectral region above $390 \mathrm{~nm}$ but also down to wavelengths approaching the dissociative continuum starting below $243 \mathrm{~nm}$ (Maksyutenko et al., 2012). Also ab initio calculations (Polyansky et al., 2012) for this spectral region were developed.
BT2 and HITEMP include absorption features of water vapour in the wavelength range below $390 \mathrm{~nm}$, as shown in Fig. 1. Other trace gases such as $\mathrm{HCHO}, \mathrm{BrO}$ and $\mathrm{HONO}$ are retrieved in this wavelength region. However, to date, water vapour absorptions are not included in DOAS retrieval procedures. Therefore the detection of water vapour absorption below $390 \mathrm{~nm}$ and thus the possibility to improve trace gas retrievals are of great interest for DOAS measurements.

For the DOAS analysis in the UV range, IO was removed from the fit while the cross-sections listed in Table 2 were added.

During the MAX-DOAS measurements (M91) systematic residual structures in the spectral region below $370 \mathrm{~nm}$ were observed. Their amplitude of up to $6 \times 10^{-4}$ increased with decreasing elevation angle just like the $\mathrm{O}_{4}$ and/or water vapour dSCDs (at $442 \mathrm{~nm}$ ) and also the residual spectral structure showed narrow differential absorption features. This could indicate a tropospheric absorber in the spectral region below $370 \mathrm{~nm}$ - which is currently not considered in typical DOAS retrievals - such as water vapour. Due to the strong correlation of $\mathrm{O}_{4}$ and water vapour dSCDs for the MAX-DOAS measurements during the M91 campaign and insufficient detection limits for the LP-DOAS measurements, these residual structures could not be unambiguously attributed to either $\mathrm{O}_{4}$ or water vapour absorption. The variation of water vapour mixing ratios along the cruise track of M91 was not large enough to separate both possible contributions.

The water vapour absorption band around $377 \mathrm{~nm}$ could not be identified by our MAX-DOAS measurements (M91) so far and is, judging from the residual optical depth from the fit, presumably smaller than $4 \times 10^{-27} \mathrm{~cm}^{2}$ at a spectral resolution of $0.45 \mathrm{~nm}$. This is in agreement with the published values of the cross-sections shown in Fig. 1.

The specified cross-section of the absorption band at $362 \mathrm{~nm}$ is about twice as large in BT2 as in HITEMP, which is due to the line cutoff present in the HITEMP database. The absorption lines around $362 \mathrm{~nm}$ are not based on measurements but on the calculated BT2 line list, which was the starting point for the HITEMP database (Rothman et al., 2010). The effect of the cutoff in HITEMP can amount to an OD of $4 \times 10^{-4}$ for a SCD $S_{\mathrm{H}_{2} \mathrm{O}}=4 \times 10^{23}$ molec cm $^{-2}$ as seen from the difference of the convolved absorptions listed in BT2 and HITEMP around $362 \mathrm{~nm}$. Below $394 \mathrm{~nm}$ no laboratory measurements of individual water vapour absorption bands are available, as listed in Tennyson et al. (2013). Thus the absorption lines listed in HITEMP below $394 \mathrm{~nm}$ originate from BT2.

Furthermore, the retrieval of this band from atmospheric spectra would be difficult due to uncertainties of the overlaying absorption of the collision-induced absorption by the oxygen dimer $\mathrm{O}_{4}$. Independent of the employed literature $\mathrm{O}_{4}$ cross-section in our DOAS evaluation, the suspected water vapour absorption appears to be present in our measurement data, but the instability of the fit with respect to the used fit in- 
Table 8. Comparison of LP-DOAS data with data from the meteorological station at the CVAO: the measured mixing ratio $m$ is compared to the calculated mixing ratio $w$ from the data of the weather station. $f(w)=a \cdot w+c$ and $f_{0}(w)=a_{0} \cdot w$ are fitted measurement errorweighted to the observations $m$. The correlation coefficient or Pearson's $R$ is constant for all cases. The best agreement in overall absorption size in the W3 interval is observed for HITRAN 2009. The uncertainty of the meteorological measurements is estimated to result in a relative uncertainty in water vapour mixing ratio of $7 \%$. The relative observed slopes $a$ and $a_{0}$ agree with expectations from Table 3 .

\begin{tabular}{lrrrr}
\hline Source of cross-section data & $a$ & $c(\%)$ & $a_{0}$ & $R$ \\
\hline HITRAN 2009 & $1.02 \pm 0.03$ & $-0.45 \pm 0.80$ & $1.004 \pm 0.003$ & 0.93 \\
HITEMP & $0.93 \pm 0.03$ & $-0.40 \pm 0.70$ & $0.918 \pm 0.002$ & 0.93 \\
BT2 & $0.90 \pm 0.03$ & $-0.41 \pm 0.69$ & $0.882 \pm 0.002$ & 0.93 \\
\hline
\end{tabular}

terval and large residual structures close to the possible water absorption indicate that there is still a significant mismatch between measurement and modelled absorption lines.

$\mathrm{Du}$ et al. (2013) reported measurements of the water vapour absorption cross-section by ring-down spectroscopy of pure water vapour in the $290-350 \mathrm{~nm}$ region sampling the absorption cross-section in steps of $5 \mathrm{~nm}$. They report that their measurements are in agreement with previous determinations of the absorption at $442.73 \mathrm{~nm}$. The reported cross-section values of $\sigma_{\max }=2.94 \times 10^{-24} \mathrm{~cm}^{-2} \mathrm{molec}^{-1}$ at $330 \mathrm{~nm}$ exceed the maximum absorption of the BT2 line list in the spectral region from 330 to $350 \mathrm{~nm}$ by 2 orders of magnitude. This would lead to an OD of $\tau=$ $S \times \sigma_{\max }=1.2$ for MAX-DOAS measurements with a SCD $S_{\mathrm{H}_{2} \mathrm{O}}=4 \times 10^{23}$ molec cm $^{-2}$ (a typical MAX-DOAS column density for mid-latitude summer conditions) under a telescope elevation angle of $3^{\circ}$, which is clearly in disagreement with our observations. Also measurements of other tropospheric trace gases such as $\mathrm{HCHO}(336.5-359 \mathrm{~nm})$ (Pinardi et al., 2013), $\mathrm{BrO}(330.6-352.75 \mathrm{~nm})$ and $\mathrm{SO}_{2}$ (314.8-326.8 nm) (Lübcke et al., 2014), which would have also been affected, did not show any unknown differential absorption of this size but did yield residual spectra with at least 2 orders of magnitude smaller amplitudes.

For MAX-DOAS measurements in the Peruvian upwelling (M91) the magnitude of the fit residual in the region from 332 to $370 \mathrm{~nm}$ was below $6 \times 10^{-4}$ peak to peak for a water vapour dSCD retrieved in the blue wavelength range of $4 \times 10^{23}$ molec $\mathrm{cm}^{-2}$, yielding an upper limit on the differential cross-section of water vapour of $3 \times 10^{-27} \mathrm{~cm}^{2} \mathrm{molec}^{-1}$ at a resolution of $0.45 \mathrm{~nm}$ under atmospheric conditions, i.e. 3 orders of magnitude smaller than the figure reported by $\mathrm{Du}$ et al. (2013) at $330 \mathrm{~nm}$.

If the shape of the water vapour cross-section presented in Du et al. (2013) could be represented by the DOAS polynomial in the respective wavelength range, it would not be detected. However, the comparably small absorption at $345 \mathrm{~nm}$ would have already resulted in a significant absorption structure with a differential absorption structure size of $6 \times 10^{-2}$, which could not have been compensated by the polynomial. Additionally, water vapour does not show an absorption cross-section which can be represented by a polynomial in other spectral regions in the visible spectral range. We therefore conclude that the cross-section values reported in Du et al. (2013) must be considerably too high, judging from UV MAX-DOAS measurements under atmospheric conditions. Alternatively the measurements of Du et al. (2013) may represent only individual absorption lines at each of the wavelengths of the reported magnitude, while in the spectral region between those measurements no cross-section data are available. Therefore the conclusion by $\mathrm{Du}$ et al. (2013) that the total impact of water vapour absorptions in middlelatitudes on the radiation flux at the ground level is be comparable to ozone between 330 and $350 \mathrm{~nm}$ cannot be supported.

At a spectral resolution of $0.5 \mathrm{~nm}$, the OD attributed to water vapour between 350 and $370 \mathrm{~nm}$ is according to HITEMP $5.5 \times 10^{-4}\left(\right.$ BT2: $\left.9.5 \times 10^{-4}\right)$ for a typical $\mathrm{H}_{2} \mathrm{O}$ dSCD of $4 \times 10^{23}$ molec $\mathrm{cm}^{-2}$. Under similar measurement conditions ( $\mathrm{dSCD}_{\mathrm{O}_{4}}=4 \times 10^{43} \mathrm{molec}^{2} \mathrm{~cm}^{-5}$ ) the OD due to $\mathrm{O}_{4}$ is $2 \times 10^{-2}$, i.e. by a factor of $20-40$ larger. The OD according to HITEMP/BT2 from 330 to $350 \mathrm{~nm}$ is comparable to the optical density of $1 \mathrm{ppt} \mathrm{BrO}$ along a light path of $10 \mathrm{~km}$ and could thus be crucial for DOAS measurements of $\mathrm{BrO}$ in the remote marine boundary layer (compare e.g. Volkamer et al., 2015). Furthermore these absorptions could contribute to the observed problems during the retrieval of tropospheric HCHO as described by Pinardi et al. (2013).

To estimate the overall influence of water vapour on the retrieval of $\mathrm{O}_{4}, \mathrm{BrO}, \mathrm{HCHO}$ and $\mathrm{HONO}$ further dedicated laboratory measurements of water vapour in this spectral region are needed.

\subsection{Error sources}

The residual spectra obtained from the DOAS evaluation procedure of the measurements were usually not dominated by photon shot noise but showed recurrent residual structures as show in Fig. 2. Since the influence of absorbers other than $\mathrm{H}_{2} \mathrm{O}$ is probably negligible, these residual structures from instrumental instabilities, saturation and $I_{0}$-effect (for MAXDOAS) should be the dominating sources of interference. Their influence on the absolute magnitude of the absorption bands is discussed in the following subsections, the influence of radiative transfer effects is discussed in Sect. 3.3.1. 


\subsubsection{Other absorbers}

For MAX-DOAS measurements the OD of absorbers other than water vapour was kept low by using a Fraunhofer reference $I_{0}(\lambda)$ recorded within the same sequence of elevation angles. Using this approach the solar zenith angle only changed slightly between the measurements and most of the stratospheric absorption by ozone and $\mathrm{NO}_{2}$ cancel out and do not affect the evaluation. Furthermore, the measurement campaigns selected took place in remote areas with surface ozone concentrations around $30-40 \mathrm{ppb}$ ozone and $\mathrm{NO}_{2}$ typically well below $1 \mathrm{ppb}$. The OD associated with $\mathrm{NO}_{2}$ was $(2 \pm 9) \times 10^{-4}$, ozone below $1.5 \times 10^{-4}$ and iodine monoxide $(2.2 \pm 2.2) \times 10^{-4}$. In comparison, the typical OD of water vapour for the wavelength intervals W0-W5 ranged up to $1.65 \times 10^{-2}$ (see Fig. 1). Since the measurements were performed on the ocean, the influence of possible VRS in liquid water on the MAX-DOAS results was tested for and not found to be significant. Changes in water vapour $\mathrm{dSCD}$ sere about $1 \%$ when including liquid water Raman scattering in the fit.

For the LP-DOAS measurements the same upper limits for the absorption of $\mathrm{NO}_{2}$ were found. The detection limits for $\mathrm{O}_{3}$, glyoxal and IO were $191 \mathrm{ppb}, 30$ and $0.36 \mathrm{ppt}$, which were not exceeded during our nightly measurements. Therefore these trace gases were not included in the final analysis.

\subsubsection{Saturation effects}

The saturation effect originates from the fact that the convolution of literature cross-sections with the instrument function does not commute with the exponential function in the Lambert-Beer Law (Wenig et al., 2005). This effect can be corrected for by replacing the absorption cross-section $\sigma(\lambda)$ by $\sigma_{\text {Sat }}^{*}(\lambda)$ given by Eq. (3) for a given column density SCD.

$\sigma_{\text {Sat }}^{*}(\lambda)=\frac{1}{S} \ln (\exp (-S \times \sigma(\lambda)) \otimes H)$

The saturation effect for a dSCD of $6 \times 10^{23} \mathrm{molec}^{-2}$ would reduce the apparent OD for the strongest absorption discussed here at $442 \mathrm{~nm}$ by about $2 \%$. A significant influence of the saturation effect on the results presented here can therefore be ruled out. This consideration is supported by the observed linear relationship between the retrieved water vapour SCDs retrieved for weaker (W1) and stronger (W3) absorption bands shown in Fig. 3.

\subsubsection{The solar $I_{0}$ effect}

The solar $I_{0}$ effect (Platt et al., 1997) describes the effective weighting of the absorption cross-section when the spectrum of the light source is highly structured itself, such as that of the Sun.

This needs to be corrected for MAX-DOAS measurements only, since the light source of LP-DOAS systems have usu- ally broader structures than the absorbers itself. The zerothorder $I_{0}$ correction does therefore not rely on the OD of the absorber but can be corrected together with the saturation effect as described by Aliwell et al. (2002) and Vogel et al. (2013) for a fixed dSCD. For our measurements corrections were made by calculating a modified $\sigma_{I_{0}}^{*}(\lambda)$ using the Kitt Peak solar flux atlas (Chance and Kurucz, 2010):

$\sigma_{I_{0}}^{*}(\lambda)=\frac{1}{S} \ln \left(\frac{\left(I_{0} \exp (-S \times \sigma(\lambda))\right) \otimes H}{I_{0} \otimes H}\right)$.

The $I_{0}$ effect can result in changes of apparent crosssection in MAX-DOAS measurements of up to $10 \%$. Because these changes can reduce as well as enhance the apparent OD, the data were evaluated with and without solar $I_{0}$ correction to estimate its effect on the relative absorption strength of different water vapour absorption bands. The data shown in Table 5 are $I_{0}$-corrected and the $I_{0}$ effect accounts here for changes of at most $2 \%$. Including the $I_{0}$ effect resulted in a significant reduction of the residual and therefore the fit errors. For the MAX-DOAS evaluation, a SCD for the $I_{0}$ correction of $1 \times 10^{15} \mathrm{molec} \mathrm{cm}^{-2}$ for $\mathrm{NO}_{2}, 1 \times 10^{18}$ molec cm $\mathrm{cm}^{-2}$ for $\mathrm{O}_{3}$ and $3 \times 10^{23}$ molec cm $\mathrm{cm}^{-2}$ for $\mathrm{H}_{2} \mathrm{O}$ was applied.

\section{Discussion}

From the fit errors listed in Table 6 especially for the weak absorption features of water vapour, it can be seen that the development of water vapour absorption compilations from HITRAN 2009 to HITEMP/HITRAN 2012 results in a better fit of the measurement data. The fit errors for the intervals (W0 to W5) of the water vapour absorption cross-section are reduced. Changing from HITRAN 2009 to HITEMP or BT2 reduces nearly all fit errors somewhat; the reduction is dramatic (20-75\%) for the weaker bands (W1, W2 and W4). The smallest relative fit errors are observed for most absorption bands for HITEMP.

The magnitude of the main absorption W3 at $442 \mathrm{~nm}$ agrees with data from a meteorological station as shown in Table 8 .

Nevertheless, the relative absorptions of different groups of absorption lines are inconsistent and do not fit our measurements; they are listed relative to $\mathrm{W} 3$ in Table 5. In the BT2 line list and in HITEMP the absorptions from 410 to $434 \mathrm{~nm}$ overestimate the observed absorptions approximately by a factor of 2 .

Tennyson (2014) noted that the absorption line intensities for transitions involving highly excited vibrational states can depend strongly on the representation of the dipole moment surfaces in the ab initio models, particularly for transitions involving bending modes. This could be in agreement with our observations, since the largest discrepancy between modelled and measured absorptions was observed for the $7 v+\delta$ polyad. 
As it turned out in Sect. 4.1 a separation of the crosssection into separate cross-sections for different bend mode values $v_{2}$ indicates that the difference in relative absorption strength can be attributed to absorption lines with higher bend mode values. Their intensities are systematically overestimated (Table 7).

- For W0 (394-410 nm) the results from MAX-DOAS and LP-DOAS agree that the magnitude of the absorption at $\mathrm{W} 0$ is found to be about $5 \pm 6 \%$ smaller in measurements than what is reported in HITEMP.

- For W1 (410-423.5 nm) the agreement of MAX-DOAS and LP-DOAS measurements is not as good, since the overall absorption is about half as large as W0. The absorption of this group of absorption lines is too high by $60 \pm 10 \%$ in HITEMP. For W1 in BT2 a better agreement is found, together with smaller fit errors. Even when considering the overestimation of the absorption W1 in HITEMP, the fit error was reduced from HITRAN 2009 to HITEMP. This shows that the shape of the absorption is reproduced more accurately in HITEMP.

- The absorption W2 $(423.5-434 \mathrm{~nm})$ was not regularly identified in LP-DOAS measurements and is also close to the magnitude of the residuals for MAX-DOAS data. Therefore the result for W2 should be viewed with caution. The shape of the water cross-section is reproduced correctly within $1 \times 10^{-27} \mathrm{~cm}^{2}$ at $0.45 \mathrm{~nm}$ resolution. HITEMP overestimates this absorption compared to observations by $30 \pm 25 \%$, BT2 by even $82 \pm 33 \%$, but its shape is reproduced better in HITEMP than in HITRAN 2009, as seen from the smaller fit errors.

- The absorption W3 (434-451.5 nm) is relatively strong and therefore requires application of saturation and $I_{0}$ corrections. Furthermore, neglecting the changes in radiative transfer for MAX-DOAS measurements for individual absorption lines leads to significant structures in the residual spectra (up to $5 \times 10^{-4}$ ), while the overall water vapour dSCD is only slightly changed by $<3 \%$ for $\mathrm{S}<5 \times 10^{23} \mathrm{molec}^{-2}$. The simple approximation of having a constant light path for the MAX-DOAS observation within this wavelength interval does not hold here for larger OD; therefore the fit errors also do not decrease, as seen for the BT2 list for LP-DOAS measurements in Table 6.

- The absorption W4 (451.5-461.5 nm) is small, but absorptions in this wavelength range could interfere with measurements of glyoxal. In fact the optical density due to $\mathrm{H}_{2} \mathrm{O}$ is comparable to previous observations of glyoxal on the open ocean (e.g. Mahajan et al., 2014): $\mathrm{dSCD}_{\text {Glyoxal }}=1 \times 10^{15} \mathrm{molec} \mathrm{cm}^{-2}$ corresponds to $6 \times$ $10^{-4}$ at $455 \mathrm{~nm}, \mathrm{dSCD}_{\mathrm{H}_{2} \mathrm{O}}=4 \times 10^{23}$ molec cm $^{-2}$ to
$4 \times 10^{-4}$ for HITEMP at $456 \mathrm{~nm}$ ) which also absorbs in this spectral region. A water vapour dSCD-correlated structure in the residuals is found at the absorption at $453.0 \mathrm{~nm}$ (HITEMP), which can also be seen in Fig. 2. This absorption seems to be better reproduced in BT2, the absorption is at $452.5 \mathrm{~nm}$. The same error estimate for the convolved cross-section as for W2 applies for W4.

- For W5 (461.5-480 nm) good agreement for water vapour absorption based on HITEMP, HITRAN 2009 and BT2 was found in observed LP-DOAS spectra within an error of $4 \%$. W5 was not within the measured wavelength range of the MAX-DOAS instrument.

On the basis of the observed discrepancies in relative absorption band strength, we suggest rescaling the respective water vapour absorption cross-section or including only wavelength intervals in a DOAS analysis where the relative absorption band strengths are sufficiently in agreement with each other. This means e.g. for IO that the water absorption band at $442 \mathrm{~nm}$ (W3) should be avoided when the absorption at $426 \mathrm{~nm}$ (W2) or even also at $416 \mathrm{~nm}$ (W1) is included. For the retrieval of glyoxal with its main spectral absorption features above $440 \mathrm{~nm}$, a wavelength window which does not include water vapour absorption at 426 and $416 \mathrm{~nm}$ should be preferred when using these water vapour absorption crosssections. The same argument applies for choosing a retrieval interval for $\mathrm{NO}_{2}$.

The relative strength of the absorption band W5 around $470 \mathrm{~nm}$ and the small fit errors indicate that the water vapour absorption cross-section is unlikely to cause interferences when retrieving $\mathrm{O}_{4}$ dSCDs for radiative transfer modelling in this spectral region.

The water absorptions included in HITEMP below $390 \mathrm{~nm}$ were observed in our measurements and found to be smaller than $\sigma_{\max }=4 \times 10^{-27} \mathrm{~cm}^{2}$ for the $377 \mathrm{~nm}$ region for a spectral resolution of $0.45 \mathrm{~nm}$. Absorptions observed in the $362 \mathrm{~nm}$ region might be caused by water vapour or by uncertainties of $\mathrm{O}_{4}$ cross-sections. Here absorptions with ODs of $4 \times 10^{-4}$ correspond to water vapour dSCDs of $3 \times 10^{23} \mathrm{molec} \mathrm{cm}^{-2}$ (BT2) or $6 \times 10^{23} \mathrm{molec} \mathrm{cm}^{-2}$ (HITEMP), which are realistic dSCDs in mid-latitude regions. Typical $\mathrm{O}_{4}$ absorptions in MAX-DOAS measurements in this regions are of the order of $2 \times 10^{-2}$. Since the $\mathrm{O}_{4} \mathrm{ab}$ sorption is used to retrieve aerosol extinction profiles from MAX-DOAS data, it might be necessary to correctly compensate for water vapour absorption to obtain correct profile information. This would require more theoretical calculations and dedicated validation measurements of the water vapour absorption cross-section below $395 \mathrm{~nm}$.

Another aspect which needs to be considered is the wavelength dependence of the air mass factor in MAX-DOAS measurements covering several significant absorption bands, which implies that low residuals can only be obtained when accounting for these effects. For example, for a water vapour 
Table 9. Correction factors for HITRAN 2009, HITEMP and BT2, calculated as error-weighted means of the values derived from MAXDOAS and LP-DOAS observations listed in Table 5 relative to W3. Values listed in square brackets in Table 5 were not used. When both values in Table 5 are above a relative fit error of $25 \%$, only the MAX-DOAS values are used and listed in square brackets. The relative error for each of these values listed in Table 5 was estimated to be twice the fit error listed in Table 6 .

\begin{tabular}{|c|c|c|c|c|c|c|c|}
\hline $\begin{array}{l}\text { Dominating polyad } \\
\text { Name }\end{array}$ & & $\begin{array}{r}8 v \\
\text { W0 }\end{array}$ & $\begin{array}{r}7 v+\delta \\
\mathrm{W} 1\end{array}$ & W2 & $\begin{array}{r}7 v \\
\mathrm{~W} 3\end{array}$ & W4 & $\begin{array}{r}6 v+\delta \\
\mathrm{W} 5\end{array}$ \\
\hline Start of interval & $(\mathrm{nm})$ & 394.0 & 410.0 & 423.5 & 434.0 & 451.5 & 461.5 \\
\hline End of interval & $(\mathrm{nm})$ & 410.0 & 423.5 & 434.0 & 451.5 & 461.5 & 480.0 \\
\hline \multicolumn{8}{|c|}{$\begin{array}{l}\text { Source of cross-section } \\
\text { data }\end{array}$} \\
\hline HITRAN 2009 & & $1.06 \pm 0.07$ & $1.95 \pm 0.04$ & {$[1.69 \pm 1.14]$} & 1 & {$[0.31 \pm 0.25]$} & $1.02 \pm 0.07$ \\
\hline HITEMP & & $1.05 \pm 0.06$ & $0.63 \pm 0.04$ & $0.77 \pm 0.15$ & 1 & $0.36 \pm 0.11$ & $1.03 \pm 0.07$ \\
\hline BT2 & & $1.06 \pm 0.05$ & $0.48 \pm 0.03$ & $0.55 \pm 0.10$ & 1 & $0.395 \pm 0.10$ & $1.01 \pm 0.06$ \\
\hline
\end{tabular}

dSCD of $5 \times 10^{23}$ molec $\mathrm{cm}^{-2}$ these effects will lead to residual structures of $\approx 2.5 \times 10^{-4}$ when including W1-W3 or already $\approx 1 \times 10^{-4}$ within W3 itself (compare also Table 4).

\section{Conclusions}

The revised line compilations HITEMP and BT2 lead to considerable improvements in DOAS measurements of water vapour and other trace gases. In particular, lowering the threshold above which absorption lines are included in the HITRAN database as well as theoretical and experimental progress led to improved water vapour absorption crosssections in the blue wavelength range.

We showed that the water vapour absorption fit errors of the DOAS retrieval can be reduced by up to $20-75 \%$ by using current water vapour absorption cross-sections (e.g. HITEMP: Rothman et al., 2010) compared to older versions of HITRAN. This shows that the shape of the water vapour absorption is better reproduced by the HITEMP, reducing the amplitude of residual spectra. When the error in the relative magnitude of several absorption bands are corrected (e.g. by scaling the water vapour absorption cross-sections in the different spectral intervals), the amplitude of residual spectra for larger fit intervals can be reduced significantly (compare e.g. Fig. 2), which then allows more reliable retrieval of weak absorbers.

Each of the water vapour absorption cross-sections evaluated here (HITRAN 2009, HITRAN 2012, HITEMP and BT2) was found to have certain limitations for the use in DOAS retrievals in the blue wavelength range. Even after water absorption cross-sections have improved they are still not sufficiently accurate for modern high-precision DOAS measurements of tropospheric trace gases at mid-latitudes. Fit errors obtained from evaluating measurement data were found to become lower for individual absorption features with the improvement of the HITRAN database from HITRAN 2009 to HITEMP and HITRAN 2012. However, we also showed that there are still problems concerning the relative strength of the different absorption bands in the blue wavelength range which need to be addressed.

The correction factor for different absorption bands from 394 to $480 \mathrm{~nm}$, which we derived from our atmospheric measurements listed in Table 9. They range from 0.5 to 1.9 and are highly significant. Even the most recent water vapour absorption cross-section (HITRAN 2012) still requires the application of correction factors ranging between 0.63 and 1.0. The corrections are necessary for all high-precision DOAS measurements in this spectral range when significant water vapour absorption is present. The here-presented correction factors can be used until better absorption line lists are available. Inclusion of even weaker absorption lines in the databases could further improve the modelling of water vapour optical densities, as indicated by the minimum in fit errors of LP-DOAS data when using the BT2 line list without a threshold for the absolute magnitude of the cross-section of individual absorption lines. From our measurements, water vapour absorptions below $385 \mathrm{~nm}$ remain uncertain and do not match current water vapour absorption cross-section data. We could not confirm recent UV water vapour absorption cross-section measurements by $\mathrm{Du}$ et al. (2013) and found upper limits for the absorption cross-section which are 2 orders of magnitude lower. Therefore further research to provide more consistent water vapour absorption crosssection data in the UV/VIS range is necessary.

High-quality LP-DOAS measurements along light-path lengths of $\approx 10 \mathrm{~km}$ and a comparably high spectral resolution in a tropical climate seem to be feasible in order to investigate further the relative absorption band strength without the need to correct for radiative transfer effects, especially the study of different vibrational states outlined in Sect. 4.1.

Acknowledgements. We thank J. Tennyson, H. Sihler and K. Großmann, R. Volkamer, T. Koenig, the editor and the two referees for helpful comments during the preparation of the manuscript. 
We thank the captain, officers and crew of Meteor for support during cruise M91. We thank the CVAO team, especially L. Mendes, for support during the HALOCAVE campaign. We thank GEOMAR for logistical support. We thank the German Science foundation DFG within the core program METEOR/MERIAN. We thank the German ministry of education and research (BMBF) for supporting this work within the SOPRAN (Surface Ocean Processes in the Anthropocene) project (Förderkennzahl: FKZ 03F0662F) which is embedded in SOLAS. We thank the University of York/NCAS (National Centre for Atmospheric Science) for providing meteorological measurement data at CVAO. We thank the authorities in Peru for the permission to work in their territorial waters.

The article processing charges for this open-access publication were covered by the Max Planck Society.

Edited by: A. Richter

\section{References}

Aliwell, S. R., Roozendael, M. V., Johnston, P. V., Richter, A., Wagner, T., Arlander, D. W., Burrows, J. P., Jones, D. J., Tornkvist, K. K., Lambert, J.-C., Pfeilsticker, K., and Pundt, I.: Analysis for $\mathrm{BrO}$ in Zenith-sky spectra: An intercomparision exercise for analysis improvement, J. Geophys. Res., 107, ACH 10-1-ACH 10-20, doi:10.1029/2001JD000329, 2002.

Bange, H.: FS Poseidon Fahrtbericht/Cruise Report P399-2\&3: Eastern tropical North Atlantic; P399-2: 31 April 201017 June 2010 Las Palmas - Las Palmas (Canary Islands), P399-3: 18-24 June 2010 Las Palmas (Canary Islands) - Vigo (Spain); DRIVE (Diurnal and RegIonal Variability of Halogen Emmissions), SOPRAN, Cruise Report doi:10.3289/ifmgeomar_rep_48_2011, IFM-GEOMAR, Kiel, available at: http: //oceanrep.geomar.de/12032/ (last access: October 2015), 2011.

Bange, H.: Surface Ocean - Lower Atmosphere Study (SOLAS) in the upwelling region off Peru - Cruise No.M91, DFGSenatskommission fuer Ozeanographie, METEOR-Berichte, 91, 69 pp., doi:10.2312/cr_m91, available at: https://portal.geomar. de/metadata/leg/show/316029 (last access: October 2015), 2013.

Barber, R. J., Tennyson, J., Harris, G. J., and Tolchenov, R. N.: A high-accuracy computed water line list, Mon. Not. R. Astron. Soc., 368, 1087-1094, doi:10.1111/j.13652966.2006.10184.x, available at: http://mnras.oxfordjournals. org/content/368/3/1087.abstract (last access: October 2015), 2006.

Bleisch, R. and Kampfer, N.: Retrieval of tropospheric water vapour profiles by using spectra from a microwave spectro-radiometer at $22 \mathrm{GHz}$, in: Microwave Radiometry and Remote Sensing of the Environment (MicroRad), 5-9 March 2012, 12th Specialist Meeting on Microwave Radiometry and Remote Sensing of the Environment (MicroRad), 1-3, IEEE, 2012.

Bussemer, M.: Der Ring-Effekt: Ursachen und Einfluß auf die spektroskopische Messung stratosphärischer Spurenstoffe, Diploma thesis, Heidelberg University, Heidelberg, Germany, 47-55, 1993.

Cantrell, C. A.: Technical Note: Review of methods for linear leastsquares fitting of data and application to atmospheric chemistry problems, Atmos. Chem. Phys., 8, 5477-5487, doi:10.5194/acp8-5477-2008, 2008.

Carpenter, L., Fleming, Z., Read, K., Lee, J., Moller, S., Hopkins, J., Purvis, R., Lewis, A., Müller, K., Heinold, B., Herrmann, H., Fomba, K., van Pinxteren, D., Müller, C., Tegen, I., Wiedensohler, A., Müller, T., Niedermeier, N., Achterberg, E., Patey, M., Kozlova, E., Heimann, M., Heard, D., Plane, J., Mahajan, A., Oetjen, H., Ingham, T., Stone, D., Whalley, L., Evans, M., Pilling, M., Leigh, R., Monks, P., Karunaharan, A., Vaughan, S., Arnold, S., Tschritter, J., Pöhler, D., Frieß, U., Holla, R., Mendes, L., Lopez, H., Faria, B., Manning, A., and Wallace, D.: Seasonal characteristics of tropical marine boundary layer air measured at the Cape Verde Atmospheric Observatory, J. Atmos. Chem., 67, 87-140, doi:10.1007/s10874-011-9206-1, 2010.

Chance, K. and Kurucz, R.: An improved high-resolution solar reference spectrum for earth's atmosphere measurements in the ultraviolet, visible, and near infrared, J. Quant. Spectrosc. Ra., 111, 1289-1295, doi:10.1016/j.jqsrt.2010.01.036, 2010.

Chance, K. and Orphal, J.: Revised ultraviolet absorption cross sections of $\mathrm{H}_{2} \mathrm{CO}$ for the HITRAN database, J. Quant. Spectrosc. Ra., 112, 1509-1510, doi:10.1016/j.jqsrt.2011.02.002, 2011.

Coburn, S., Dix, B., Sinreich, R., and Volkamer, R.: The CU ground MAX-DOAS instrument: characterization of RMS noise limitations and first measurements near Pensacola, FL of BrO, IO, and CHOCHO, Atmos. Meas. Tech., 4, 2421-2439, doi:10.5194/amt-4-2421-2011, 2011.

Deutschmann, T., Beirle, S., Friess, U., Grzegorski, M., Kern, C., Kritten, L., Platt, U., Prados-Roman, C., Pukīte, J., Wagner, T., Werner, B., and Pfeilsticker, K.: The Monte Carlo atmospheric radiative transfer model McArtim: Introduction and validation of Jacobians and 3D features, J. Quant. Spectrosc. Ra., 112, 11191137, doi:10.1016/j.jqsrt.2010.12.009, 2011.

Dix, B., Baidar, S., Bresch, J. F., Hall, S. R., Schmidt, K. S., Wang, S., and Volkamer, R.: Detection of iodine monoxide in the tropical free troposphere, P. Natl. Acad. Sci. USA, 110, 2035-2040, doi:10.1073/pnas.1212386110, 2013.

Du, J., Huang, L., Min, Q., and Zhu, L.: The influence of water vapor absorption in the 290-350nm region on solar radiance: Laboratory studies and model simulation, Geophys. Res. Lett., 40, 4788-4792, doi:10.1002/grl.50935, 2013.

Fleischmann, O.: New ultraviolet absorption cross-sections of $\mathrm{BrO}$ at atmospheric temperatures measured by time-windowing Fourier transform spectroscopy, J. Photoch. Photobio. A, 168, 117-132, 2004.

Frankenberg, C.: Retrieval of methane and carbon monoxide using near infrared spectra recorded by SCIAMACHY onboard ENVISAT, Dissertation, Institut für Umweltphysik, Universität Heidelberg, 129-138, 2005.

Frieß U., Monks, P. S., Remedios, J. J., Rozanov, A., Sinreich, R., Wagner, T., and Platt, U.: MAX-DOAS $\mathrm{O}_{4}$ measurements: A new technique to derive information on atmospheric aerosols: 2. Modeling studies, J. Geophys. Res., 111, D14203, doi:10.1029/2005JD006618, 2006.

Frieß, U., Deutschmann, T., Gilfedder, B. S., Weller, R., and Platt, U.: Iodine monoxide in the Antarctic snowpack, Atmos. Chem. Phys., 10, 2439-2456, doi:10.5194/acp-10-2439-2010, 2010.

Fuhlbrügge, S., Quack, B., Atlas, E., Fiehn, A., Hepach, H., and Krüger, K.: Meteorological constraints on oceanic halocarbons 
above the Peruvian Upwelling, Atmos. Chem. Phys. Discuss., 15, 20597-20628, doi:10.5194/acpd-15-20597-2015, 2015.

Grainger, J. and Ring, J.: Anomalous Fraunhofer line profiles, Nature, 193, p. 762, 1962.

Greenblatt, G. D., Orlando, J. J., Burkholder, J. B., and Ravishankara, A. R.: Absorption Measurements of Oxygen between 330 and 1140 nm, J. Geophys. Res., 95, 18577-18582, 1990.

Großmann, K., Frieß, U., Peters, E., Wittrock, F., Lampel, J., Yilmaz, S., Tschritter, J., Sommariva, R., von Glasow, R., Quack, B., Krüger, K., Pfeilsticker, K., and Platt, U.: Iodine monoxide in the Western Pacific marine boundary layer, Atmos. Chem. Phys., 13, 3363-3378, doi:10.5194/acp-13-3363-2013, 2013.

Hepach, H., Quack, B., Ziska, F., Fuhlbrügge, S., Atlas, E. L., Krüger, K., Peeken, I., and Wallace, D. W. R.: Drivers of diel and regional variations of halocarbon emissions from the tropical North East Atlantic, Atmos. Chem. Phys., 14, 1255-1275, doi:10.5194/acp-14-1255-2014, 2014.

Hermans, C., Vandaele, A. C., Carleer, M., Fally, S., Colin, R., Jenouvrier, A., Coquart, B., and Mérienne, M.-F.: Absorption Cross-Sections of Atmospheric Constituents: $\mathrm{NO}_{2}, \mathrm{O}_{2}$, and $\mathrm{H}_{2} \mathrm{O}$, Environ. Sci. \& Pollut. Res., 6, 151-158, 1999.

Hill, C., Yurchenko, S. N., and Tennyson, J.: Temperaturedependent molecular absorption cross sections for exoplanets and other atmospheres, Icarus, 226, 1673-1677, doi:10.1016/j.icarus.2012.07.028, 2013.

Hönninger, G. and Platt, U.: Observations of BrO and its vertical distribution during surface ozone depletion at Alert, Atmos. Environ., 36, 2481-2489, 2002.

Hönninger, G., von Friedeburg, C., and Platt, U.: Multi axis differential optical absorption spectroscopy (MAX-DOAS), Atmos. Chem. Phys., 4, 231-254, doi:10.5194/acp-4-231-2004, 2004.

Kraus, S.: DOASIS - A Framework Design for DOAS, Dissertation, Heidelberg University, 33-72, 2006.

Kuntz, M.: A new implementation of the Humlicek algorithm for the calculation of the Voigt profile function, J. Quant. Spectrosc. Ra., 57, 819-824, doi:10.1016/S0022-4073(96)00162-8, 1997.

Lampel, J., Frieß, U., and Platt, U.: The impact of vibrational Raman scattering of air on DOAS measurements of atmospheric trace gases, Atmos. Meas. Tech., 8, 3767-3787, doi:10.5194/amt-8-3767-2015, 2015.

Lübcke, P., Bobrowski, N., Arellano, S., Galle, B., Garzón, G., Vogel, L., and Platt, U.: $\mathrm{BrO} / \mathrm{SO}_{2}$ molar ratios from scanning DOAS measurements in the NOVAC network, Solid Earth, 5, 409-424, doi:10.5194/se-5-409-2014, 2014.

Mahajan, A. S., Prados-Roman, C., Hay, T. D., Lampel, J., Pöhler, D., Großmann, K., Tschritter, J., Frieß, U., Platt, U., Johnston, P., Kreher, K., Wittrock, F., Burrows, J. P., Plane, J. M., and Saiz-Lopez, A.: Glyoxal observations in the global marine boundary layer, J. Geophys. Res.-Atmos., 119, 6160-6169, doi:10.1002/2013JD021388, 2014.

Maksyutenko, P., Grechko, M., Rizzo, T. R., and Boyarkin, O. V.: State-resolved spectroscopy of high vibrational levels of water up to the dissociative continuum, Philos. T. R. Soc. A, 370, 27102727, 2012.

Murphy, W. F.: The rovibrational Raman spectrum of water vapour v1 and v3, Mol. Phys., 36, 727-732, 1978.

Myhre, G., Shindell, D., Bréon, F.-M., Collins, W., Fuglestvedt, J., Huang, J., Koch, D., Lamarque, J.-F., Lee, D., Mendoza, B., Nakajima, T., Robock, A., Stephens, G., Takemura, T., and
Zhang, H.: Anthropogenic and natural radiative forcing, in: Climate Change 2013: The Physical Science Basis. Contribution of Working Group I to the Fifth Assessment Report of the Intergovernmental Panel on Climate Change, edited by: Stocker, T., Qin, D., Plattner, G.-K., Tignor, M., Allen, S., Boschung, J., Nauels, A., Xia, Y., Bex, V., and Midgley, P., 659-740, Cambridge University Press, Cambridge, United Kingdom and New York, NY, USA, doi:10.1017/CBO9781107415324.018, 2013.

Neri, F., Saitta, G., and Chiofalo, S.: An accurate and straightforward approach to line regression analysis of error-affected experimental data, J. Phys. E Sci. Instrum., 22, 215-217, 1989.

Penney, C. M. and Lapp, M.: Raman-scattering cross sections for water vapor, J. Opt. Soc. Am., 66, 422-425, doi:10.1364/JOSA.66.000422, 1976.

Peters, E., Wittrock, F., Richter, A., Alvarado, L. M. A., Rozanov, V. V., and Burrows, J. P.: Liquid water absorption and scattering effects in DOAS retrievals over oceans, Atmos. Meas. Tech., 7, 4203-4221, doi:10.5194/amt-7-4203-2014, 2014.

Pinardi, G., Van Roozendael, M., Abuhassan, N., Adams, C., Cede, A., Clémer, K., Fayt, C., Frieß, U., Gil, M., Herman, J., Hermans, C., Hendrick, F., Irie, H., Merlaud, A., Navarro Comas, M., Peters, E., Piters, A. J. M., Puentedura, O., Richter, A., Schönhardt, A., Shaiganfar, R., Spinei, E., Strong, K., Takashima, H., Vrekoussis, M., Wagner, T., Wittrock, F., and Yilmaz, S.: MAXDOAS formaldehyde slant column measurements during CINDI intercomparison and analysis improvement, Atmos. Meas. Tech., 6, 167-185, doi:10.5194/amt-6-167-2013, 2013.

Platt, U. and Stutz, J.: Differential optical absorption spectroscopy, Springer, Berlin, Heidelberg, 135-158, 2008.

Platt, U., Marquard, L., Wagner, T., and Perner, D.: Corrections for Zenith Scattered Light DOAS, Geophys. Res. Letters, 24, 17591762, 1997.

Pöhler, D., Vogel, L., Frieß, U., and Platt, U.: Observation of halogen species in the Amundsen Gulf, Arctic, by active long-path differential optical absorption spectroscopy, P. Natl. Acad. Sci. USA, 107, 6582-6587, doi:10.1073/pnas.0912231107, 2010.

Polyansky, O. L., Zobov, N. F., Mizus, I. I., Lodi, L., Yurchenko, S. N., Tennyson, J., Császár, A. G., and Boyarkin, O. V.: Global spectroscopy of the water monomer, Philos. T. R. Soc. A, 370, 2728-2748, 2012.

Prados-Roman, C., Cuevas, C. A., Hay, T., Fernandez, R. P., Mahajan, A. S., Royer, S.-J., Galí, M., Simó, R., Dachs, J., Großmann, K., Kinnison, D. E., Lamarque, J.-F., and Saiz-Lopez, A.: Iodine oxide in the global marine boundary layer, Atmos. Chem. Phys., 15, 583-593, doi:10.5194/acp-15-583-2015, 2015.

Read, K. A., Mahajan, A. S., Carpenter, L. J., Evans, M. J., Faria, B. V. E., Heard, D. E., Hopkins, J. R., Lee, J. D., Moller, S. J., Lewis, A. C., Mendes, L., McQuaid, J. B., Oetjen, H., Saiz-Lopez, A., Pilling, M. J., and Plane, J. M. C.: Extensive halogen-mediated ozone destruction over the tropical Atlantic Ocean., Nature, 453, 1232-1235, doi:10.1038/nature07035, 2008.

Rizi, V., Iarlori, M., Rocci, G., and Visconti, G.: Raman LIDAR Observations of Cloud Liquid Water, Appl. Opt., 43, 6440-6453, doi:10.1364/AO.43.006440, 2004.

Rothman, L., Gordon, I., Barbe, A., Benner, D., Bernath, P., Birk, M., Boudon, V., Brown, L., Campargue, A., Champion, J.-P., Chance, K., Coudert, L., Dana, V., Devi, V., Fally, S., Flaud, J.M., Gamache, R., Goldman, A., Jacquemart, D., Kleiner, I., Lacome, N., Lafferty, W., Mandin, J.-Y., Massie, S., Mikhailenko, 
S., Miller, C., Moazzen-Ahmadi, N., Naumenko, O., Nikitin, A., Orphal, J., Perevalov, V., Perrin, A., Predoi-Cross, A., Rinsland, C., Rotger, M., Šimečková, M., Smith, M., Sung, K., Tashkun, S., Tennyson, J., Toth, R., Vandaele, A., and Auwera, J. V.: The HITRAN 2008 molecular spectroscopic database, J. Quant. Spectrosc. Ra., 110, 533-572, doi:10.1016/j.jqsrt.2009.02.013, 2009.

Rothman, L., Gordon, I., Barber, R., Dothe, H., Gamache, R., Goldman, A., Perevalov, V., Tashkun, S., and Tennyson, J.: HITEMP, the high-temperature molecular spectroscopic database, J. Quant. Spectrosc. Ra., 111, 2139-2150, doi:10.1016/j.jqsrt.2010.05.001, 2010.

Rothman, L., Gordon, I., Babikov, Y., Barbe, A., Benner, D. C., Bernath, P., Birk, M., Bizzocchi, L., Boudon, V., Brown, L., Campargue, A., Chance, K., Cohen, E., Coudert, L., Devi, V., Drouin, B., Fayt, A., Flaud, J.-M., Gamache, R., Harrison, J., Hartmann, J.-M., Hill, C., Hodges, J., Jacquemart, D., Jolly, A., Lamouroux, J., Roy, R. L., Li, G., Long, D., Lyulin, O., Mackie, C., Massie, S., Mikhailenko, S., Müller, H., Naumenko, O., Nikitin, A., Orphal, J., Perevalov, V., Perrin, A., Polovtseva, E., Richard, C., Smith, M., Starikova, E., Sung, K., Tashkun, S., Tennyson, J., Toon, G., Tyuterev, V., and Wagner, G.: The HITRAN2012 molecular spectroscopic database, J. Quant. Spectrosc. Ra., 130, 4-50, doi:10.1016/j.jqsrt.2013.07.002, 2013.

Sansonetti, C. J., Salit, M. L., and Reader, J.: Wavelengths of spectral lines in mercury pencil lamps, Appl. Opt., 35, 74-77, doi:10.1364/AO.35.000074, 1996.

Schönhardt, A., Begoin, M., Richter, A., Wittrock, F., Kaleschke, L., Gómez Martín, J. C., and Burrows, J. P.: Simultaneous satellite observations of IO and $\mathrm{BrO}$ over Antarctica, Atmos. Chem. Phys., 12, 6565-6580, doi:10.5194/acp-12-6565-2012, 2012.

Seitz, K., Buxmann, J., Pöhler, D., Sommer, T., Tschritter, J., Neary, T., O'Dowd, C., and Platt, U.: The spatial distribution of the reactive iodine species IO from simultaneous active and passive DOAS observations, Atmos. Chem. Phys., 10, 2117-2128, doi:10.5194/acp-10-2117-2010, 2010.

Serdyuchenko, A., Gorshelev, V., Weber, M., Chehade, W., and Burrows, J. P.: High spectral resolution ozone absorption crosssections - Part 2: Temperature dependence, Atmos. Meas. Tech., 7, 625-636, doi:10.5194/amt-7-625-2014, 2014

Shefov, N. N.: Intensivnosti nokotorykh emissiy sumerochnogo i nochnogo neba (Intensities of some Emissions of the Twilight and Night Sky), Spectral, electrophotometrical and radar researches of aurorae and airglow, IGY program, section IV, 1, 25, 1959.

Sinreich, R., Coburn, S., Dix, B., and Volkamer, R.: Ship-based detection of glyoxal over the remote tropical Pacific Ocean, Atmos. Chem. Phys., 10, 11359-11371, doi:10.5194/acp-1011359-2010, 2010.

Smirnov, A., Holben, B. N., Slutsker, I., Giles, D. M., McClain, C. R., Eck, T. F., Sakerin, S. M., Macke, A., Croot, P., Zibordi, G., Quinn, P. K., Sciare, J., Kinne, S., Harvey, M., Smyth, T. J., Piketh, S., Zielinski, T., Proshutinsky, A., Goes, J. I., Nelson, N. B., Larouche, P., Radionov, V. F., Goloub, P., Krishna Moorthy, K., Matarrese, R., Robertson, E. J., and Jourdin, F.: Maritime Aerosol Network as a component of Aerosol Robotic Network, J. Geophys. Res.-Atmos., 114, D06204, doi:10.1029/2008JD011257, 2009.

Spietz, P., Gómez Martín, J. C., and Burrows, J. P.: Spectroscopic studies of the $\mathrm{I}_{2} / \mathrm{O}_{3}$ photochemistry: Part 2. Im- proved spectra of iodine oxides and analysis of the IO absorption spectrum, J. Photoch. Photobio. A, 176, 50-67, doi:10.1016/j.jphotochem.2005.08.023, 2005.

Stutz, J. and Platt, U.: Numerical Analysis and Estimation of the Statistical Error of Differential Optical Absorption Spectroscopy Measurements with Least-Squares methods, Appl. Opt., 35, 6041-6053, 1996.

Tennyson, J.: Vibration-rotation transition dipoles from first principles, J. Mol. Spectrosc., 298, 1-6, 2014.

Tennyson, J. and Yurchenko, S. N.: ExoMol: molecular line lists for exoplanet and other atmospheres, Mon. Not. R. Astron. Soc., 425, 21-33, 2012.

Tennyson, J., Zobov, N. F., Williamson, R., Polyansky, O. L., and Bernath, P. F.: Experimental energy levels of the water molecule, J. Phys. Chem. Ref. Data, 30, 735-831, 2001.

Tennyson, J., Bernath, P. F., Brown, L. R., Campargue, A., Csaszar, A. G., Daumont, L., Gamache, R. R., Hodges, J. T., Naumenko, O. V., Polyansky, O. L., Rothman, L. S., Vandaele, A. C., Zobov, N. F., Derzi, A. R. A., Fabri, C., Fazliev, A. Z., Furtenbacher, T., Gordon, I. E., Lodi, L., and Mizus, I. I.: IUPAC critical evaluation of the rotational-vibrational spectra of water vapor, Part III: Energy levels and transition wavenumbers for $\mathrm{H}_{2}^{16} \mathrm{O}$, J. Quant. Spectrosc. Ra., 117, 29-58, doi:10.1016/j.jqsrt.2012.10.002, 2013.

Thalman, R. and Volkamer, R.: Temperature dependent absorption cross-sections of $\mathrm{O}_{2}-\mathrm{O}_{2}$ collision pairs between 340 and 630 $\mathrm{nm}$ and at atmospherically relevant pressure, Phys. Chem. Chem. Phys., 15, 15371-15381, doi:10.1039/C3CP50968K, 2013.

Thalman, R., Baeza-Romero, M. T., Ball, S. M., Borrás, E., Daniels, M. J. S., Goodall, I. C. A., Henry, S. B., Karl, T., Keutsch, F. N., Kim, S., Mak, J., Monks, P. S., Muñoz, A., Orlando, J., Peppe, S., Rickard, A. R., Ródenas, M., Sánchez, P., Seco, R., Su, L., Tyndall, G., Vázquez, M., Vera, T., Waxman, E., and Volkamer, R.: Instrument intercomparison of glyoxal, methyl glyoxal and $\mathrm{NO} 2$ under simulated atmospheric conditions, Atmos. Meas. Tech., 8, 1835-1862, doi:10.5194/amt-8-1835-2015, 2015.

Vandaele, A., Hermans, C., Simon, P., Carleer, M., Colin, R., Fally, S., Merienne, M., Jenouvrier, A., and Coquart, B.: Measurements of the $\mathrm{NO}_{2}$ absorption cross-section from $42000 \mathrm{~cm}^{-1}$ to 10000 $\mathrm{cm}^{-1}(238-1000 \mathrm{~nm})$ at $220 \mathrm{~K}$ and $294 \mathrm{~K}$, J. Quant. Spectrosc. Ra., 59, 171-184, doi:10.1016/S0022-4073(97)00168-4, 1998.

Vandaele, A. C., Hermans, C., Fally, S., Carleer, M., Colin, R., Mérienne, M.-F., Jenouvrier, A., and Coquart, B.: Highresolution Fourier transform measurement of the $\mathrm{NO}_{2}$ visible and near-infrared absorption cross sections: temperature and pressure effects, J. Geophys. Res., 107, 4348, doi:10.1029/2001JD000971, 2002.

Vogel, L., Sihler, H., Lampel, J., Wagner, T., and Platt, U.: Retrieval interval mapping: a tool to visualize the impact of the spectral retrieval range on differential optical absorption spectroscopy evaluations, Atmos. Meas. Tech., 6, 275-299, doi:10.5194/amt6-275-2013, 2013.

Volkamer, R., Spietz, P., Burrows, J. P., and Platt, U.: Highresolution absorption cross-section of Glyoxal in the UV/vis and IR spectral ranges, J. Photoch. Photobio. A: Chemistry, 172, 3546, 2005.

Volkamer, R., Baidar, S., Campos, T. L., Coburn, S., DiGangi, J. P., Dix, B., Eloranta, E. W., Koenig, T. K., Morley, B., Ortega, I., Pierce, B. R., Reeves, M., Sinreich, R., Wang, S., Zondlo, 
M. A., and Romashkin, P. A.: Aircraft measurements of BrO, IO, glyoxal, $\mathrm{NO}_{2}, \mathrm{H}_{2} \mathrm{O}, \mathrm{O}_{2}-\mathrm{O}_{2}$ and aerosol extinction profiles in the tropics: comparison with aircraft-/ship-based in situ and lidar measurements, Atmos. Meas. Tech., 8, 2121-2148, doi:10.5194/amt-8-2121-2015, 2015.

Vountas, M., Richter, A., Wittrock, F., and Burrows, J. P.: Inelastic scattering in ocean water and its impact on trace gas retrievals from satellite data, Atmos. Chem. Phys., 3, 1365-1375, doi:10.5194/acp-3-1365-2003, 2003.

Wagner, T., Deutschmann, T., and Platt, U.: Determination of aerosol properties from MAX-DOAS observations of the Ring effect, Atmos. Meas. Tech., 2, 495-512, doi:10.5194/amt-2-4952009, 2009.

Wagner, T., Andreae, M. O., Beirle, S., Dörner, S., Mies, K., and Shaiganfar, R.: MAX-DOAS observations of the total atmospheric water vapour column and comparison with independent observations, Atmos. Meas. Tech., 6, 131-149, doi:10.5194/amt6-131-2013, 2013a.
Wagner, T., Beirle, S., Sihler, H., and Mies, K.: A feasibility study for the retrieval of the total column precipitable water vapour from satellite observations in the blue spectral range, Atmos. Meas. Tech., 6, 2593-2605, doi:10.5194/amt-6-2593-2013, 2013b.

Wang, H., Liu, X., Chance, K., González Abad, G., and Chan Miller, C.: Water vapor retrieval from OMI visible spectra, Atmos. Meas. Tech., 7, 1901-1913, doi:10.5194/amt-7-1901-2014, 2014.

Wenig, M., Jähne, B., and Platt, U.: Operator representation as a new differential optical absorption spectroscopy formalism, Appl. Opt., 44, 3246-3253, doi:10.1364/AO.44.003246, 2005.

Yilmaz, S.: Retrieval of Atmospheric Aerosol and Trace Gas Vertical Profiles using Multi-Axis Differential Optical Absorption Spectroscopy, Dissertation, Institut für Umweltphysik, Heidelberg University, 67-81, 2012. 